\title{
Transcriptome analysis of smooth cordgrass (Spartina alterniflora Loisel), a monocot halophyte, reveals candidate genes involved in its adaptation to salinity
}

Renesh Bedre ${ }^{1+}$, Venkata Ramanarao Mangu ${ }^{1+}$, Subodh Srivastava ${ }^{2}$, Luis Eduardo Sanchez ${ }^{1,3}$ and Niranjan Baisakh ${ }^{1 *}$

\begin{abstract}
Background: Soil salinity affects growth and yield of crop plants. Plants respond to salinity by physiological and biochemical adjustments through a coordinated regulation and expression of a cascade of genes. Recently, halophytes have attracted attention of the biologists to understand their salt adaptation mechanisms. Spartina alterniflora (smooth cordgrass) is a Louisiana native monocot halophyte that can withstand salinity up to double the strength of sea water. To dissect the molecular mechanisms underlying its salinity adaptation, leaf and root transcriptome of S. alterniflora was sequenced using 454/GS-FLX.
\end{abstract}

Results: Altogether, 770,690 high quality reads with an average length 324-bp were assembled de novo into 73,131 contigs (average 577-bp long) with 5.9X sequence coverage. Most unigenes (95\%) annotated to proteins with known functions, and had more than $90 \%$ similarity to rice genes. About $28 \%$ unigenes were considered specific to S. alterniflora. Digital expression profiles revealed significant enrichment $(P<0.01)$ of transporters, vacuolar proton pump members and transcription factors under salt stress, which suggested the role of ion homeostasis and transcriptional regulation in the salinity adaptation of this grass. Also, 10,805 SSRs markers from 9457 unigenes were generated and validated through genetic diversity analysis among 13 accessions of S. alterniflora.

Conclusions: The present study explores the transcriptome of S. alterniflora to understand the gene regulation under salt stress in halophytes. The sequenced transcriptome (control and salt-regulated) of S. alterniflora provides a platform for further gene finding studies in grasses. This study and our previously published studies suggested that S. alterniflora is a rich reservoir of salt tolerance genes that can be used to develop salt tolerant cereal crops, especially rice, a major food crop of global importance.

Keywords: Gene expression, GS-FLX, Salinity, Spartina alterniflora, Transcriptome

Abbreviations: DEG, Differentially expressed gene; FDR, False discovery rate; GO, Gene ontology; LC, Leaf control; LS, Stressed leaf; nr, Non-redundant; RC, Root control; RS, Stressed root; SSR, Simple sequence repeat; TF, Transcription factor; TR, Transcription regulator

\footnotetext{
* Correspondence: nbaisakh@agcenter.Isu.edu

${ }^{\dagger}$ Equal contributors

${ }^{1}$ School of Plant, Environmental and Soil Sciences, Louisiana State University

Agricultural Center, Baton Rouge, LA 70803, USA

Full list of author information is available at the end of the article
} 


\section{Background}

Soil salinity negatively affects growth and development of plants by impairing the physiological and biochemical processes, thereby reducing crop yield and quality, or in severe case, death of the plant [1-3]. Salinity causes constant reduction in arable lands [4], and rise in the sea water level due to inevitable global climate change will only worsen this situation in future. This is further complicated by the increasing salinity of irrigation water in dry areas, perpetual hurricanes that result in inundation of sea water into cultivated land, etc. Future agricultural production will rely on our ability to develop and grow salt tolerant food and fiber crops in salt-affected areas [5]. Most crop plants are sensitive to salt stress and the extent of damage varies with the species, genotypes within a species, phenology of the plant, and the severity of soil salinity. Conventional breeding has exploited the understanding of the genetic basis of salt tolerance and the genotypic variations within primary and secondary gene pools to develop salt tolerant crops. However, the progress to this end has been slow and little due to the complexity and multigenic inheritance with low to moderate heritability of salt tolerance traits [6]. Therefore, systems level understanding of plant biology, physiology, genetics and biochemistry of salt stress responses is required to translate the knowledge to designing salt tolerant crops. Substantial progress has been made in the past in the understanding and identification of different salt tolerance mechanisms in the model glycophyte Arabidopsis thaliana. However, translation of Arabidopsis resources to more distant crops, such as rice, has been limited due to significant differences in their signal transduction and gene regulatory networks [7].

Halophytes have the ability to complete their life cycle at a salt concentration of at least $200 \mathrm{mM} \mathrm{NaCl}$ or up to $5 \mathrm{~g} / \mathrm{l}$ of total dissolved salt in irrigation water $[8,9]$, whereas most sensitive crop plants, such as rice, can be severely affected at as low as 20 to $50 \mathrm{mM} \mathrm{NaCl}$ [10]. A true halophyte remains viable at or beyond sea water salinity $[11,12]$. Optimal growth of halophytes is observed at soil salinity between 200 to $400 \mathrm{mM} \mathrm{NaCl}$ [13]. Several mechanisms are known to be operational at the cellular, organizational, and whole plant level in halophytes for their adaptation to soil salinity [14]. Genetically, high tolerance to salinity in halophytes may be due to (1) superior gene regulatory mechanism, (2) superior alleles of salt-responsive genes, and (3) presence of unique/novel genes or processes [15]. Importantly, halophytes have comparative advantages over glycophytes in their ability to determine the nature of transporters involved in the uptake toxic $\mathrm{Na}^{+}$[16], accumulation of high concentrations of $\mathrm{K}^{+}[12]$, and preferential accumulation of salt (up to $50 \%$ of shoot dry weight) to balance osmotic potential [9]. Comparative expression profiling studies of Thellungiella halophila with A. thaliana suggested that differences in the regulatory networks involved in stress perception and subsequent triggering of stress-responsive genes in halophytes may account for their stress anticipatory preparedness and superior adaptation responses [15, 17-19].

Previous studies on halophytes have mostly been focused on dicot halophytes, such as T. halophila due to its close similarity with $A$. thaliana. Transfer of such knowledge to major cereal food crops like rice has been limited due to differences in developmental and anatomical features associated with salt tolerance mechanisms of dicot and monocot halophytes. For example, dicots, being succulent, accumulate more $\mathrm{Na}^{+}$in their shoots than monocot halophytes [20]. Therefore, an effort to develop and exploit molecular genetic resources of wild relatives within cereal species is necessary to identify loci involved in environmental adaptation and their subsequent translation to improve salinity tolerance of cereals [21]. But, wild relatives of a crop (e.g., rice), which has long term adaptability to salinity, may not always exist. This warrants for elucidation of regulation of adaptive processes of a grass halophyte involved in response to high and prolonged salinity [12].

Among different monocotyledonous halophytes, Spartina alterniflora (smooth cordgrass), a dominant salt marsh grass along the Atlantic and gulf coasts of the U.S., has exceptionally high tolerance to salinity, and is known to possess all possible mechanisms of salt tolerance, such as ion exclusion at root level and ion secretion in leaves through salt glands [22], vacuolar sequestration of toxic $\mathrm{Na}^{+}$[23], maintenance of reduced osmotic potential through synthesis and accumulation of compatible solutes [24] and maintenance of photosynthesis [25]. S. alterniflora is an aneu-hexaploid $(2 \mathrm{n}=$ $6 \mathrm{x}=62$ ) belonging to the subfamily Chloridoideae of family Poaceae [26]. Flow cytometry analysis showed that among Spartina species, S. alterniflora has the largest genome (1763.9 Mbp), more than four times of the size of the rice genome [27]. Previous studies with small-scale transcriptome analysis showed that $S$. alterniflora showed 80-90\% similarity to rice at the DNA and protein sequences level [28, 29]. Furthermore, Agrobacterium-mediated introgression of S. alterniflora genes, such as vacuolar $\mathrm{H}^{+}$-ATPase subunit c1 (SaVHAc1), adenosine diphosphate ribosylation factor (SaARF1) and myo-inositol phosphate synthase (SaINO1), into rice, Arabidopsis and tobacco has demonstrated abiotic stress tolerance of transgenic overexpressers [30-32].

In addition to its extreme salt adaptability, S. alterniflora is also described as a very good model to study recent allopolyploid speciation [33]. While the present study was in progress, a paper was published on the development of a reference transcriptome of S. alterniflora [34]. Some 
ecologically relevant genes known to be involved in salt and metal stress response were identified from this study, but no effort was made specifically to study its transcriptome that is induced or regulated under salt stress. In the present study, we performed a genome-wide transcriptome analysis of $S$. alterniflora with an objective to identify candidate genes on a global scale that possibly play roles in its ability to adapt to extremely saline habitat.

\section{Methods}

\section{Plant material and RNA isolation}

Cuttings of $S$. alterniflora with a single runner were planted in 4-in. plastic pots (one per pot) filled with sand and were placed in a deep plastic container filled with $8 \mathrm{~L}$ Hoagland's nutrient solution. The plants were grown inside a greenhouse maintained at $29 / 22{ }^{\circ} \mathrm{C}$ day/ night temperature with $14 \mathrm{~h}$ light $\left(200 \mu \mathrm{M} \mathrm{m}^{-2} \mathrm{~s}^{-1}\right)$. The solution was replenished every week. One-month-old plants with 3-4 leaves were subjected to salinity stress $(500 \mathrm{mM} \mathrm{NaCl})$. Leaf and root tissues were harvested in liquid nitrogen from plants before salt stress (control) and after $6,12,24$ and $72 \mathrm{~h}$ of salt stress, and stored at $-80{ }^{\circ} \mathrm{C}$ for RNA extraction. Three plants (biological replicates) were sampled for each time point.

\section{RNA extraction, library preparation, sequencing and assembly}

Total RNA was purified from the control and saltstressed leaf and root tissues using RNeasy plant minikit (Qiagen, Valencia, CA). RNA from different time points ( $2 \mu \mathrm{g}$ each) were pooled for leaf (stressed leaf-LS) and root (stressed root-RS) separately. Ten $\mu$ g of RNA from $\mathrm{SL}, \mathrm{SR}$, and control leaf (LC) and root (RC) tissues were subjected to RiboMinus kit (Invitrogen, Carlsbad, CA) to deplete the ribosomal RNA. Complementary DNA was synthesized from ribominusRNA and then normalized using a Trimer-2 normalization kit (Evrogen, Russia) to minimize representation of commonly abundant transcripts. A total of $500 \mathrm{ng}$ of normalized cDNA were sequenced in two half plates on the Roche's 454 GS-FLX platform (MoGene, St. Louis, MO).

Sequences were cleaned for 454 sequence primers midi tags used for multiplexing using an in-house Perl script. Low quality sequences $($ score $<20)$ and reads matching to noncoding RNAs, such as tRNA, and miRNA and snRNA, predicted using tRNAscan-SE tool with eukaryote parameters and RFAM v10.1 covariance models in INFERNAL format (http://rfam.xfam.org/), were also removed prior to further analysis. The remaining reads were assembled using CAP3 [35], separately for four libraries, LC, LS, RC and RS with default parameters where $90 \%$ minimum match on at least $100 \mathrm{bp}$ was executed that allowed a perfect match to satisfy the minimum alignment score for assembly. The stringency of assembly was kept low as suggested by [34] to assemble possible homologous reads to construct consensus contigs to constitute de novo transcriptome with expectedly up to six allelic transcripts per locus for the hexaploid grass. Assembly was validated by comparing the sequence identity of the de novo contigs against homologous ESTs reported earlier [29]. Singletons less than $50 \mathrm{bp}$ were not included in further analysis. Also, realignment of the sequence reads against the assembled unigenes was performed as a further validation using Bowtie version 1.1.0 [36], which supports realignment of reads up to $1024 \mathrm{bp}$, with three mismatches and no gaps.

\section{Functional annotation}

Spartina alterniflora unigenes (contigs and singletons) were functionally annotated by sequence similarity search against NCBI protein and nucleotide (http://www.ncbi.nlm.nih.gov/), SwissProt and TrEMBL (http://www.uniprot.org/help/uniprotkb) non-redundant (nr) plant sequence database using BLASTx and BLASTn algorithm at 1e-06 threshold. Top hits based on significant match of the alignments were parsed using in-house Perl script into MySQL database. The linear regression analysis for finding the relation of length and annotation was performed using SAS v.9.3 (SAS, 2011). Further, based on the significant hits obtained with NCBI nr database, the pathways in which genes are involved were retrieved from the Kyoto Encyclopedia of Genes and Genomes (KEGG) pathway database. The gene ontology (GO) terms and IDs of the functionally annotated S. alterniflora unigenes were assigned on the basis of BLAST against plant GOslim set and compared with Oryza sativa GOslim terms using GOslim viewer (http://agbase.msstate.edu/ cgi-bin/tools/goslimviewer_select.pl). The GOslim enrichment analysis was performed using BinGO tool [37] and visualized using Cytoscape. The hypergeometric test with false discovery rate (FDR) correction methods [38] was used for $\mathrm{GO}$ enrichment analysis to assess overrepresentation of GOslim categories.

Protein families represented in the $S$. alterniflora transcriptome were predicted by HMMsearch program of HMMER v3.0 against the hidden Markov models (HMMs) Pfam-A v26.0 database (http://pfam.xfam.org/) at e-value threshold 1.0. The database contains a set of high quality, manually curated and annotated models, and is considered as a good source for finding protein families [39, 40]. The output obtained from HMM search was parsed by an in-house Perl script and further analysis was performed using MySQL.

\section{Syntenic block analysis}

To find the syntenic block of the S. alterniflora transcriptome relative to rice chromosomes, we performed the BLASTn search against all 55,986 gene loci of the 
rice transcriptome database (rice genome annotation project release 7) at 1e-05 threshold. The sequences showing identity greater than $60 \%$ were considered as syntenic block. Further, chromosomal location of the syntenic blocks was assigned based on the physical location of these sequences on the respective rice chromosomes. A karyotype file was generated using an in-house Perl script for Circos plot of rice chromosomes and MySQL database was used for generating the connecting lines (link) to represent similar blocks between S. alterniflora and rice, and color-highlighting syntenic regions (input) on rice chromosomes. A comparative GC content analysis of $S$. alterniflora transcriptome relative to rice transcriptome was performed using in-house Perl script.

\section{Identification of gene families}

For defining the gene families of S. alterniflora, its transcriptome was compared with the transcriptomes of three monocots - Oryza sativa (Os), Zea mays ( $\mathrm{Zm}$ ) and Sorghum bicolor $(\mathrm{Sb})$ individually and together in groups. The coding sequences of the three monocot species were downloaded from the https://phytozome.jgi.doe.gov/pz/ portal.html (v8) for BLASTn analysis at 1e-20 with at least $60 \%$ similarity in the aligned region. The results were clustered using Markov Cluster algorithm [41] with default inflation (I) value of 6 to define gene families. The 4-way Venn diagram representing gene families from all four species was created using $R$ package.

\section{Identification of lineage- and species-specific genes}

Lineage- and $S$. alterniflora-specific genes were identified by sequential comparative similarity searches within the nucleotide and protein sequences available in plant kingdom to exclude the sequences conserved outside the family poaceae and within poaceae. BLASTx, and BLASTn algorithms were used for stepwise search at threshold e-value 1e-01. The potential reason for keeping low e-value cut-off is due to comparatively large number of smaller sequences in S. alterniflora transcriptome. First, all sequences of $S$. alterniflora were searched against all non-poaceae species proteome dataset available at phytozome v10 (https://phytozome.jgi.doe.gov/ pz/portal.html) with BLASTx algorithm. The sequences that showed significant hit to given non-poaceae peptide sequences were filtered out for further analysis. The remaining sequences were searched against PlantGDB (http://www.plantgdb.org), UniProtKB (http://www.uniprot.org) and NCBI $\mathrm{nr} / \mathrm{nt}$ and unigenes (http:// www.ncbi.nlm.nih.gov) for non-poaceae species. The transcripts with significant hit to these databases were filtered out. The remaining genes, which are putative members of poaceae and Spartina specific groups, were further analyzed with poaceae family genes from same database as mentioned above. The genes showing significant hits to the poaceae database were filtered out and grouped into poaceae-specific genes. Thus, the remaining transcripts that did not show any hit to any database mentioned above were termed as Spartina-specific genes. The filtering of the sequences at different stages was carried out using custom Perl script and MySQL. The GC content analysis was performed by custom Perl script.

\section{Identification of transcription factors (TFs), protein kinases, and transporters}

For the identification of TFs in S. alterniflora, its unigenes were BLAST searched with 1e-05 threshold and aligned region identity of $80 \%$ against all 29,473 protein sequences representing $\mathrm{TFs}$ and transcription regulators within 84 families of major plant species available at plant transcription factors database v3.0 (http://plntfdb.bio.unipotsdam.de/v3.0/; [42]. The fold change expression of each family member under salt stress relative to control was determined from the normalized transcript abundance based on their reads. The differentially up- and downregulated TFs were represented in a heat map as described earlier [43]. Similarly, comparative analysis of $S$. alterniflora unigenes similar to kinases was performed with kinome from rice phylogenomic database (http:// ricephylogenomics.ucdavis.edu/kinase/genInfo.shtml; [44]. The protein phosphatases in S. alterniflora transcriptome were analyzed through domain search by InterProScan (v5) using PFAM and SMART database. For comparative analysis with rice, the phosphatase domain of rice transcriptome was retrieved from the rice genome project database v7.

\section{Differential gene expression analysis}

Gene expression in S. alterniflora leaf and root under salt stress was deduced from the abundance of transcripts (number of reads per contig) in comparison to unstressed control condition. The sequence reads were mapped to the rice genome sequence using BWA-SW and reads belonging to each gene model were counted. The read counts under salt and control were normalized and used to identify differentially expressed genes (DEGs) using DEGseq v1.2.2 [45]. Genes with log2 fold change $\geq 2$ and $\leq-2$ $(P<0.05)$ were categorized as significantly differentially expressed genes. The DEGs were visualized using MA plot between $M$ ( $\log 2$ fold change) and A (average of $\log 2$ fold change between control and salt stress). Validation of the digital expression analysis was performed using (semi)quantitative RT-PCR analysis as detailed earlier [30].

\section{Identification of simple sequence repeats and genic primer analysis}

Unigenes of $S$. alterniflora were searched for simple sequence repeat (SSR) motifs using MIcroSAtellite Perl 
script (MISA, http://pgrc.ipk-gatersleben.de/misa). Unigenes with SSRs of at least six for di, and five for tri, tetra, penta and hexa-nucleotides were used to design ESSR primers as described earlier [27]. The positions of the SSRs on open reading frames of the genes were determined by using gene finding software MolQuest (FGENESH+; http://linux1.softberry.com/berry.phtml). Predictive function of the sequences containing SSR motifs were retrieved from the MySQL database containing information on functional annotation of unigenes. SSRs with mononucleotide tandem repeats were not considered for downstream analysis, and SSRs with at least six contiguous repeats of di-, tri-, tetra-, penta-nucleotide and five repeats for hexa-nucleotides were used for design of SSR primers. Six SSR primers were tested in a set of $13 \mathrm{~S}$. alterniflora accessions (CP1 through CP13) using the PCR conditions and profile as described by [27].

\section{Results and discussion Sequence assembly}

A total of 770,690 raw sequencing reads with quality score of 20 (Q20) were generated from the leaf and root tissues of $S$. alterniflora with and without salt stress. The raw sequence reads are available in the NCBI SRA database under the bioproject PRJNA302213 (http:// www.ncbi.nlm.nih.gov/bioproject/PRJNA302231). The length of the reads ranged from 16 to $616 \mathrm{bp}$ with an average length of $\sim 324$ bp (Table 1), spanning 249.6 Mbp of the transcriptome. The leaf and root tissues constituted 59.7 and $40.3 \%$ of the total reads, respectively (Fig. 1a). The high quality reads were assembled into 73,131 contigs and 200,329 singlets (more than $50 \mathrm{bp}$ ), which totaled to 273,460 unigenes (Table 1). The leaf tissue accounted to $36.6 \%$ of contigs and $63.4 \%$ of singlets, whereas the root tissue accounted to $19.2 \%$ of contigs and $83.9 \%$ of singlets combined under stress and control conditions (Table 2). Short read sequence data from 454 pyrosequencing have been successfully assembled and the resulting contigs have been explored for transcriptome analysis of non-model plants like $S$. alterniflora [34]. Larger number of singletons as compared to contigs in the present study could be attributed to assembly algorithm used, low-expressing transcripts, repeat regions in the reads, artifacts in cDNA normalization, sequencing error, and/or possible contamination with other organisms [46]. But, the high match of singletons to the NCBI protein database suggested that singletons were of high quality and not the result of sequencing errors, and were likely derived from the low-expressing transcripts. In addition, realignment of $85.8 \%$ unigenes to at least one read of the transcriptome of S. alterniflora validated the quality the transcriptome. The length of the contigs ranged from 51 to $6460 \mathrm{bp}$ with an average of $577 \mathrm{bp}$, whereas the length
Table 1 Assembly and annotation of Spartina alterniflora transcriptome

\begin{tabular}{ll}
\hline Parameter & Statistics \\
\hline Number of raw reads & 770,690 \\
Number of reads in leaf tissue & 459,819 \\
Number of reads in root tissue & 310,871 \\
Total span of reads & $249.59 \mathrm{Mbp}$ \\
Average length of reads & $\sim 324 \mathrm{bp}$ \\
Number of Unigenes (50 bp or greater) & 273,460 \\
Number of Contigs (50 bp or greater) & 73,131 \\
Large Contigs (500 bp or greater) & 35,519 \\
Large Unigenes(500 bp or greater) & 39,682 \\
Number of Singletons (50 bp or greater) & 200,329 \\
Number of Unigenes (Leaf Control) & 73,552 \\
Number of Unigenes(Leaf Stress) & 68,346 \\
Number of Unigenes (Root Control) & 72,199 \\
Number of Unigenes (Root Stress) & 59,363 \\
Total span of Contigs & $42.19 \mathrm{Mbp}$ \\
Total Span of Singletons & $63.29 \mathrm{Mbp}$ \\
Transcriptome Size & $105.48 \mathrm{Mbp}$ \\
N50 length & $52.74 \mathrm{Mbp}$ \\
N50 Value & $317 \mathrm{bp}$ \\
N90 length & $94.93 \mathrm{Mbp}$ \\
N90 Value & $255 \mathrm{bp}$ \\
Longest Unigene & $6.46 \mathrm{~Kb}$ \\
Smallest Unigene & $51 \mathrm{bp}$ \\
Mean length of Unigenes & $\sim 386 \mathrm{bp}$ \\
GC content (\%) & 51.46 \\
Unigenes with significant hit (\%) & 187,571 (68.50 (25.56 \%) \\
Unigenes with unknown functions & \\
Unigenes having unique protein annotation & \\
\hline
\end{tabular}

of singlets ranged from 51 to $616 \mathrm{bp}$ with an average of $316 \mathrm{bp}$; the average length of unigenes was $386 \mathrm{bp}$ (Fig. 1b). The N50 and N90 values were $317 \mathrm{bp}$ and $255 \mathrm{bp}$, respectively. Most $(79,295)$ of the unigenes were between 401 to $500 \mathrm{bp}$ in length. The unigenes covered $105.5 \mathrm{Mbp}$ of S. alterniflora transcriptome. Considering that $10 \%$ of its genome (1,763.9 Mbp; [27] represented transcribed region, the transcriptome coverage was $0.6 \mathrm{X}$, but with a sequence coverage of 5.9X. Although the depth of coverage is low in 454 sequencing, it has the capability to capture rare transcripts because of its sequence length coverage (386 bp average unigene size in this study), and has been a powerful sequencing technology in the absence of a reference genome [47]. Interestingly, only $4.3 \%$ of the reads from this study had $100 \%$ match to previously published reads of $S$. alterniflora 

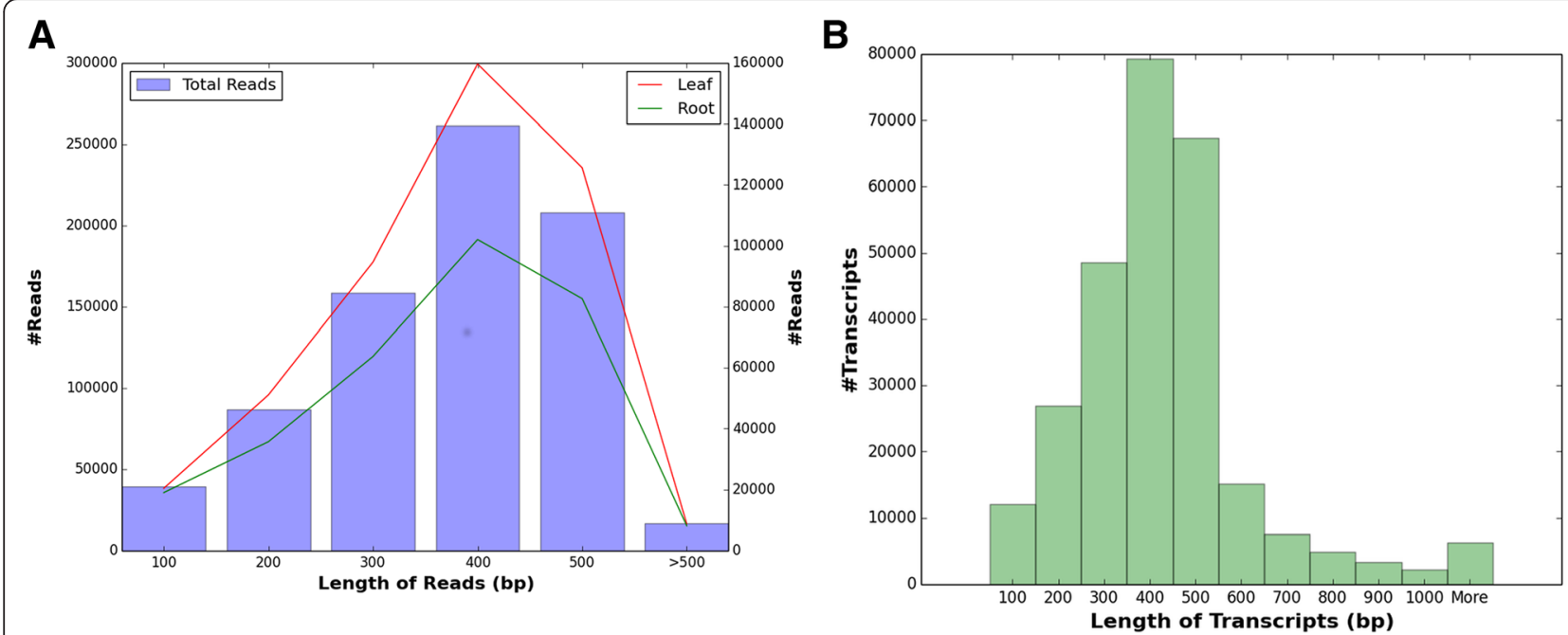

Fig. 1 a Total number of reads sequenced and their distribution in leaf and root tissue of Spartina alterniflora; b Histogram showing frequency distribution of length of Spartina alterniflora unigenes

[34], but $41.1 \%$ reads showed more than $90 \%$ match (Additional file 1).

\section{Functional annotation and GOslim analysis}

BLASTx and BLASTn searches of the unigenes against UnitprotKB and NCBI nucleotide database $(\mathrm{nr})$ showed match to total 187,571 (68.6\%) unigenes of which $61,851(33.0 \%)$ and $125,720(67.0 \%)$ were contigs and singlets, respectively. Of the total 187,571 hits, 47,960 $(25.6 \%)$ had unique hits represented in the respective database. Most (94.8 \%) of the unigenes had annotation to proteins of known function; however, 9579 (5.1\%) and $105(0.1 \%)$ had hit to hypothetical and unknown proteins, respectively. The low percentage $(68.6 \%)$ of annotation was attributed to the large number of short singleton sequences present in the dataset. Of the total unigenes, $84.9 \%$ contigs were annotated while only $62.8 \%$ singlets had annotation. The linear regression

Table 2 Sequencing and CAP3 assembly statistics of Spartina alterniflora transcriptome

\begin{tabular}{llllll}
\hline Library & $\begin{array}{l}\text { Total no. } \\
\text { of reads } \\
\text { sequenced }\end{array}$ & $\begin{array}{l}\text { Reads } \\
\text { assembled } \\
\text { into contigs }\end{array}$ & $\begin{array}{l}\text { Reads as } \\
\text { singlets }\end{array}$ & $\begin{array}{l}\% \\
\text { redundancy }\end{array}$ & $\begin{array}{l}\text { Total } \\
\text { unigenes }\end{array}$ \\
\hline $\begin{array}{l}\text { Leaf } \\
\text { Control }\end{array}$ & 239,851 & 27,691 & 45,861 & $80.87 \%$ & 73,552 \\
$\begin{array}{l}\text { Leaf } \\
\text { Stress }\end{array}$ & 219,968 & 24,237 & 44,109 & $79.94 \%$ & 68,346 \\
$\begin{array}{l}\text { Root } \\
\text { Control }\end{array}$ & 215,127 & 15,792 & 56,407 & $73.77 \%$ & 72,199 \\
$\begin{array}{l}\text { Root } \\
\text { Stress }\end{array}$ & 95,744 & 5411 & 53,952 & $43.64 \%$ & 59,363 \\
Total & 770,690 & 73,131 & 200,329 & & 273,460 \\
\hline
\end{tabular}

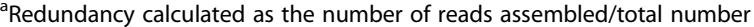
of reads analysis (Fig. 2a) showed that S. alterniflora unigene length was a significant predictor of annotation $\left(R^{2}=0.78\right.$, $P<0.0036)$. This situation was also evident in root tissues where $83.9 \%$ of the transcripts were singlets, and overall, $56.4 \%$ had BLAST matches in comparison to $79.9 \%$ transcripts $(63.4 \%$ singlets $)$ in leaf tissue (Table 2). High percentage of unigenes $(92.2 \%)$ with length $\geq 500 \mathrm{bp}$ had significant BLAST hits as compared to $64.6 \%$ unigenes having length $<500 \mathrm{bp}$. These results are in agreement with previous reports that longer sequences were more likely to annotate using BLAST searches with protein database than shorter sequences $[46,48,49]$.

Over $30 \%$ of the S. alterniflora unigenes showed more than $90 \%$ similarity with genes of Oryza sativa followed by Zea mays, Sorghum bicolor, Vitis vinifera, and Arabidopsis thaliana (Fig. 2b). S. alterniflora shares significant similarity with rice at both DNA and protein levels $[29,50]$. Therefore, rice transcriptome and genome were used as references for comparative studies of the S. alterniflora transcriptome. Only $1.5 \%$ of the unigenes showed homology with bacterial proteins, which could be due to contamination of the tissue samples, especially root. The transcripts that did not have any annotation could represent species-specific genes, untranslated regions (UTR), non-coding RNA and/or genes with novel uncharacterized function. The average GC content of S. alterniflora transcripts $(51.5 \%)$ was comparable to that of rice (51.3 \%; Additional file 2: Figure S1).

Based on the similarity to HMM profile of protein domains of Pfam-A database, 21,121 (7.7 \%) S. alterniflora unigenes were assigned to 6729 unique protein families (Additional file 3: Table S1). The KEGG pathway annotation of the transcripts revealed the diversity of pathway, 


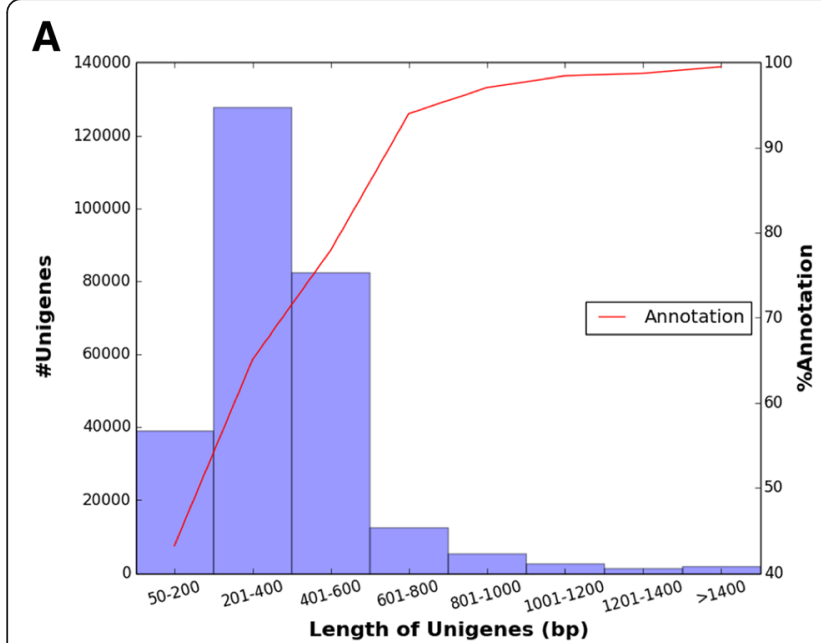

B

Fig. 2 a Total number of Spartina alterniflora unigenes and their functional annotation obtained using similarity search against NCBI and UniProt database; b Distribution of the species with genes that were highly homologous to Spartina alterniflora unigenes based on the significant hits obtained from BLAST analysis

molecular interaction in the cells and biological functions represented in the $S$. alterniflora transcriptome. Highly expressed KEGG pathways were represented by the transcripts involved in metabolic processes, such as amino acid metabolism, carbohydrate metabolism, fatty acid metabolism, and nitrogenous compound metabolism of which purine, methane and carbon metabolic processes were dominant (Fig. 3; Table 3). Phenylpropanoid biosynthesis and amino acid degradation represented major secondary metabolism pathways (Fig. 3).

The gene ontology analysis (GOslim terms) assigned 57.0, 50.0, and $43 \%$ of S. alterniflora transcripts to biological process, molecular function, and cellular component, respectively. S. alterniflora unigenes covered wide range of functional GO categories (Fig. 4a). GOslim terms for biosynthetic and transport processes were highly represented in the biological processes. Similarly, GOslim terms for catalytic activity and hydrolase were higher in the molecular function category. Plastid was the highly presented GOslim term under cellular component category. Analysis of the GOslim terms of $S$. alterniflora transcripts showed that genes involved in transport and kinase activity were highly enriched under salt stress in both leaf and root transcriptome (Fig. 4b).

\section{Synteny with rice genome}

Spartina alterniflora showed substantial similarity with rice at both DNA and protein levels (Fig. 5). Homology

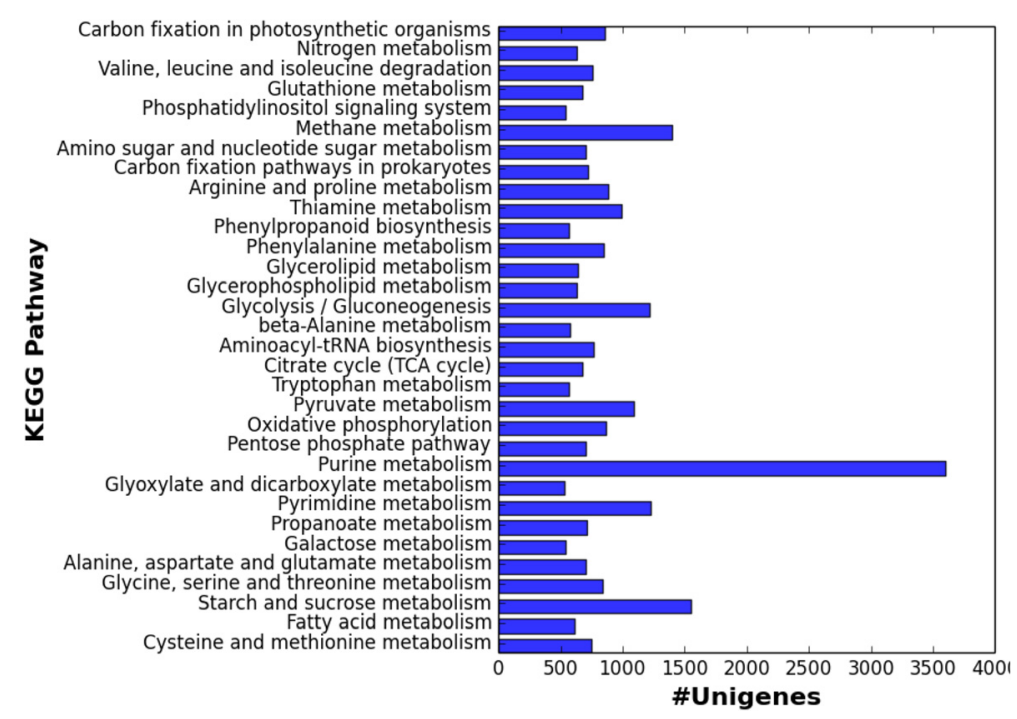

Fig. 3 Highly expressed biological pathways represented in Spartina alterniflora transcriptome retrieved from the KEGG database 
Table 3 The enzymes and their IDs for the Spartina alterniflora transcripts involved in highly expressed pathways

\begin{tabular}{|c|c|}
\hline Enzyme & ID \\
\hline L-amino-acid oxidase & ec:1.4.3.2 \\
\hline 3-hydroxybutyryl-CoA epimerase & ec:5.1.2.3 \\
\hline maltose alpha-D-glucosyltransferase & ec:5.4.99.16 \\
\hline homoserine kinase & ec:2.7.1.39 \\
\hline L-amino-acid oxidase & ec:1.4.3.2 \\
\hline 6-phosphofructokinase & ec:2.7.1.11 \\
\hline methylmalonyl-CoA epimerase & ec:5.1.99.1 \\
\hline uridine kinase & ec:2.7.1.48 \\
\hline methylmalonyl-CoA epimerase & ec:5.1.99.1 \\
\hline 5-(carboxyamino)imidazole ribonucleotide mutase & ec:5.4.99.18 \\
\hline 2-dehydro-3-deoxygluconokinase & ec:2.7.1.45 \\
\hline succinate dehydrogenase (ubiquinone) & ec:1.3.5.1 \\
\hline pyruvate kinase & ec:2.7.1.40 \\
\hline L-amino-acid oxidase & ec:1.4.3.2 \\
\hline succinate dehydrogenase (ubiquinone) & ec:1.3.5.1 \\
\hline L-seryl-tRNASec selenium transferase & ec:2.9.1.1 \\
\hline malonyl-CoA decarboxylase & ec:4.1.1.9 \\
\hline pyruvate kinase & ec:2.7.1.40 \\
\hline choline kinase & ec:2.7.1.32 \\
\hline glycerate kinase & ec:2.7.1.31 \\
\hline L-amino-acid oxidase & ec:1.4.3.2 \\
\hline 4-coumarate-CoA ligase & ec:6.2.1.12 \\
\hline hydroxymethylpyrimidine kinase & ec:2.7.1.49 \\
\hline oxaloacetate decarboxylase & ec:4.1.1.3 \\
\hline methylmalonyl-CoA epimerase & ec:5.1.99.1 \\
\hline L-arabinokinase & ec:2.7.1.46 \\
\hline glycerone kinase & ec:2.7.1.29 \\
\hline CDP-diacylglycerol_-inositol 3-phosphatidyltransferase & ec:2.7.8.11 \\
\hline gamma-glutamylcyclotransferase & ec:2.3.2.4 \\
\hline methylmalonyl-CoA epimerase & ec:5.1.99.1 \\
\hline D-amino-acid dehydrogenase & ec:1.4.99.1 \\
\hline pyruvate kinase & ec:2.7.1.40 \\
\hline
\end{tabular}

search of S. alterniflora transcriptome was done against rice transcriptome database to find syntenic regions, which showed that $\sim 50 \%$ of the S. alterniflora transcripts matched with rice transcriptome at 1e-05 cut off value (Table 4). Distribution of the $S$. alterniflora transcripts along 12 rice chromosomes showed that large numbers of $S$. alterniflora transcripts were represented in chromosome 1 of rice. However, the number of genes of rice identical to $S$. alterniflora transcripts in rice chromosome 1 was less $(44.4 \%)$ as compared to chromosome $3(48.8 \%$; Table 4$)$. The other chromosomes of rice also had an extensive similarity with S. alterniflora transcriptome. This was in congruence with previous results where the comparisons of 10 coding genes between Spartina and rice revealed low nucleotide divergence between the two species [50]. Previously we have reported that Spartina alterniflora, shares significant similarity with rice at both nucleotide and protein level $[28,29]$. This is further evident from the success of using rice oligomicroarrays for gene expression analysis in Spartina [50]. Therefore, two subfamily species, rice and Spartina, in spite of long period of divergence, apparently have maintained a high level of synteny.

\section{Gene families represented in Spartina alterniflora transcriptome}

Sequence comparison of the $S$. alterniflora transcriptome with transcriptomes of three monocots, such as $O$. sativa, Z. mays and S. bicolor helped identify different gene families. Similarity search among these Poaceae transcriptomes resulted in a total of 33,142 clusters representing different gene families. Among these, 13,262 clusters representing 158,613 genes were shared by $S$. alterniflora transcriptome with all three transcriptomes. Pair-wise comparison of S. alterniflora transcriptome with the three transcriptomes revealed that $S$. alterniflora and $O$. sativa shared maximum number of clusters (2330) containing 9817 genes followed by 1360 clusters containing 4789 genes between S. alterniflora and Z. mays, and 1046 clusters containing 3668 genes between $S$. alterniflora and S. bicolor (Additional file 2: Figure S2). Further, 1366 clusters with 1422 genes were specific to $S$. alterniflora only, which was more than the clusters specific to rice (1307). Similarity search of genes in $S$. alterniflora-specific clusters against UniProtKB database showed that most of the genes were involved in binding, transport and kinases activities (Additional file 2: Figure S3).

\section{Lineage and species-specific genes in Spartina alterniflora transcriptome}

The lineage-specific genes share similarity with genes within one taxonomic group and have no similarity with genes outside of a particular taxon [51]. The strategy of identification and characterization of lineage- and species-specific genes is dependent upon the availability of the genomic sequences for that particular species.

Out of the total 273,460 unigenes of S. alterniflora, 157,857 unigenes showed similarity to non-poaceae gene and protein sequences obtained from phytozome, NCBI $\mathrm{nr} / \mathrm{nt}$ and unigenes databases and UniProtKB. Further analysis of the remaining 115,603 unigenes showed that 37,668 unigenes were poaceae-specific; the remaining 77,935 unigenes (10,215 contigs and 67,720 singlets) 


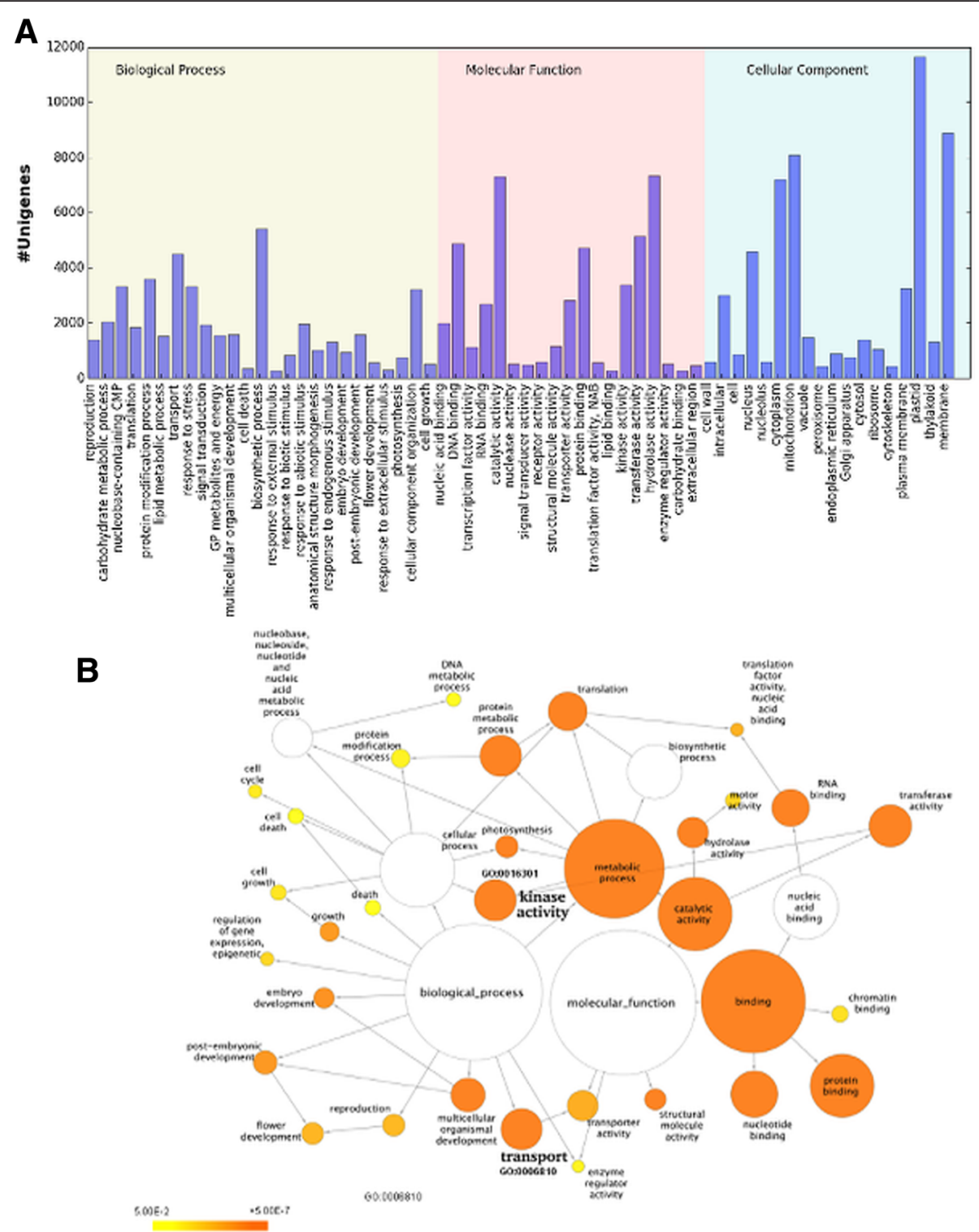

Fig. 4 a GOslim functional analysis of Spartina alterniflora genes showing their distribution in biological process, cellular component and molecular function. b Enrichment of specific GOslim terms induced under salt stress in the transcripts from leaf and root tissue

were defined as Spartina-specific genes in this study (Fig. 6). The large number of sequences specific to $S$. alterniflora in comparison to rice (17.4\%; [52] and Arabidopsis (4.9\%; [51] could be due to relatively large number of short-length singletons in S. alterniflora transcriptome or its higher genome size compared to rice and Arabidopsis. In this study, $13.8 \%$ of S. alterniflora transcripts were grouped as poaceae-specific, whereas in rice only $12.5 \%$ of genes were reported as poaceaespecific [52]. In rice, 861 genes were identified to be conserved by evolution within poaceae, but did not share similarity outside the poaceae family. This difference could be due to the larger genome size of $S$. alterniflora compared to rice. Lineage-specific genes are known to have functional and evolutionary significance such as in speciation and adaptation [51, 53].

Distribution of the GC contents for poaceae- and $S$. alterniflora-specific and non-Poaceae transcripts showed that the pattern was similar with the peak range of 48-54 \%. However, Spartina-specific transcripts did not have a broad range of GC (48.2 \%) unlike other transcripts that showed a broad range of 60-70 \% (Additional file 2: Figure S4). The results suggested that conserved poaceae-specific genes in $S$. 


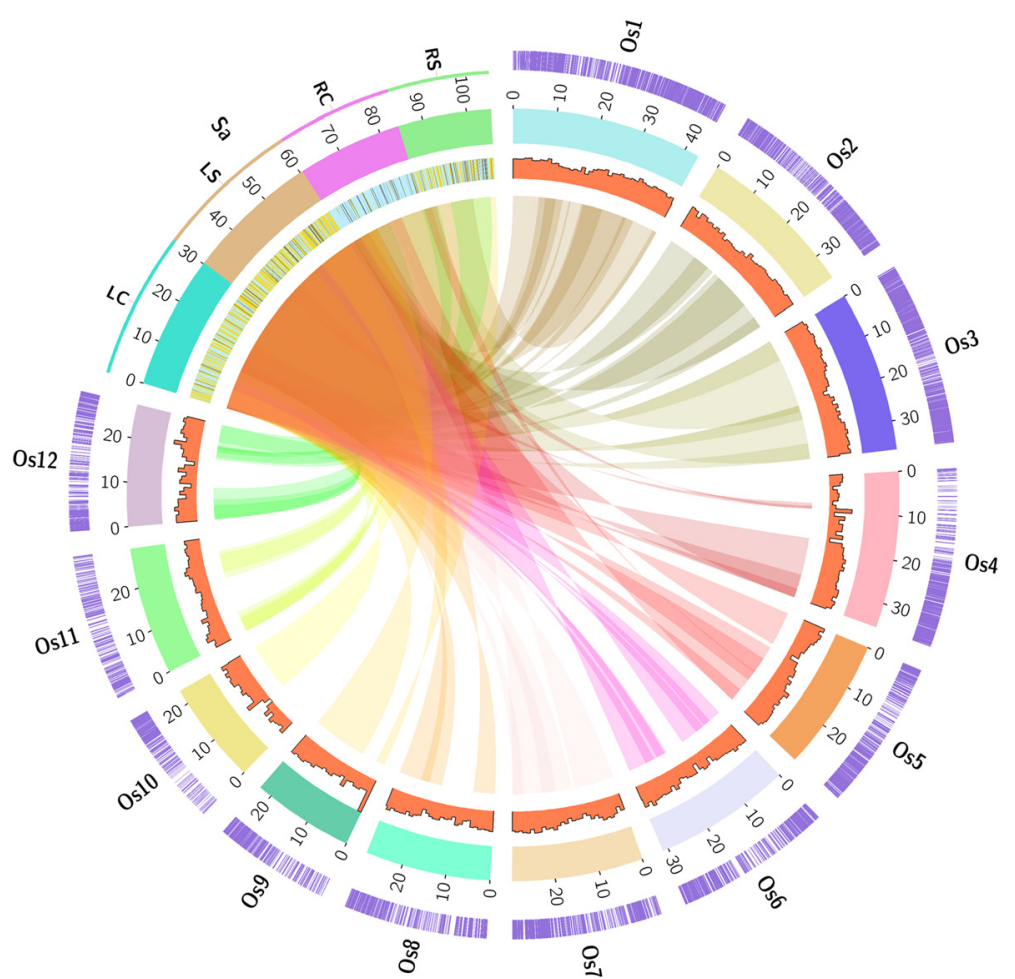

Fig. 5 Similarity shared between Spartina alterniflora transcriptome and rice genome v7.1. Sa, Spartina alterniflora; Os, individual rice chromosomes (different color boxes). Numbers outside the boxes along Os represent the size in megabase (Mbp). Syntenic blocks between Sa and Os are connected by ribbons and highlighted along the Os in purple color. Heatmap representing differential regulation of genes (yellow- upregulated and bluedownregulated) is shown on Sa transcriptome. The gene density of Sa transcripts on rice is shown by histogram

alterniflora followed similar pattern as that in rice. The characterization of the $S$. alterniflora-specific genes will lead to discovery of novel genes with species-specific functions for habitat-adaptive phenotype or traits.

\section{Differential expression of genes under salt stress}

The relative expression of transcripts under control and salt conditions in both leaf and root tissues of $S$. alterniflora offered an insight into the potential genes that may possibly be involved in salinity adaptation of the

Table 4 Mapping of assembed Spartina alterniflora transcripts onto rice genome v7.1 (downloaded from rice genome project)

\begin{tabular}{llllrl}
\hline $\begin{array}{l}\text { Rice } \\
\text { chromosome }\end{array}$ & $\begin{array}{l}\text { Total unique hits of } \\
\text { unigenes }\end{array}$ & $\begin{array}{l}\text { Total unigenes spanning rice } \\
\text { chromosome }\end{array}$ & $\begin{array}{l}\text { Total no. of genes on rice } \\
\text { chromosome }\end{array}$ & $\begin{array}{l}\text { \% rice genes covered in rice } \\
\text { chromosome }\end{array}$ & $\begin{array}{l}\text { \% unigenes } \\
\text { covered }\end{array}$ \\
\hline Os1 & 19,652 & 2898 & 6529 & 44.38 & 44.96 \\
Os2 & 15,547 & 2418 & 5377 & 48.79 & 5.18 \\
Os3 & 17,996 & 2717 & 5568 & 37.01 & 6.58 \\
Os4 & 11,413 & 1968 & 5317 & 39.17 & 3.17 \\
Os5 & 10,648 & 1791 & 4572 & 37.54 & 3.89 \\
Os6 & 10,488 & 1768 & 4709 & 36.98 & 3.83 \\
Os7 & 9873 & 1646 & 4450 & 36.46 & 3.61 \\
Os8 & 8855 & 1527 & 4188 & 36.86 & 3.23 \\
Os9 & 9380 & 1256 & 3407 & 33.81 & 3.43 \\
Os10 & 7457 & 1187 & 3510 & 30.79 & 2.72 \\
Os11 & 6101 & 1281 & 4160 & 35.74 & 3.23 \\
Os12 & 8066 & 1435 & 4014 & 55,801 & 39.23 \\
Total & 135,476 & 21,892 & & & 49.54 \\
\hline
\end{tabular}




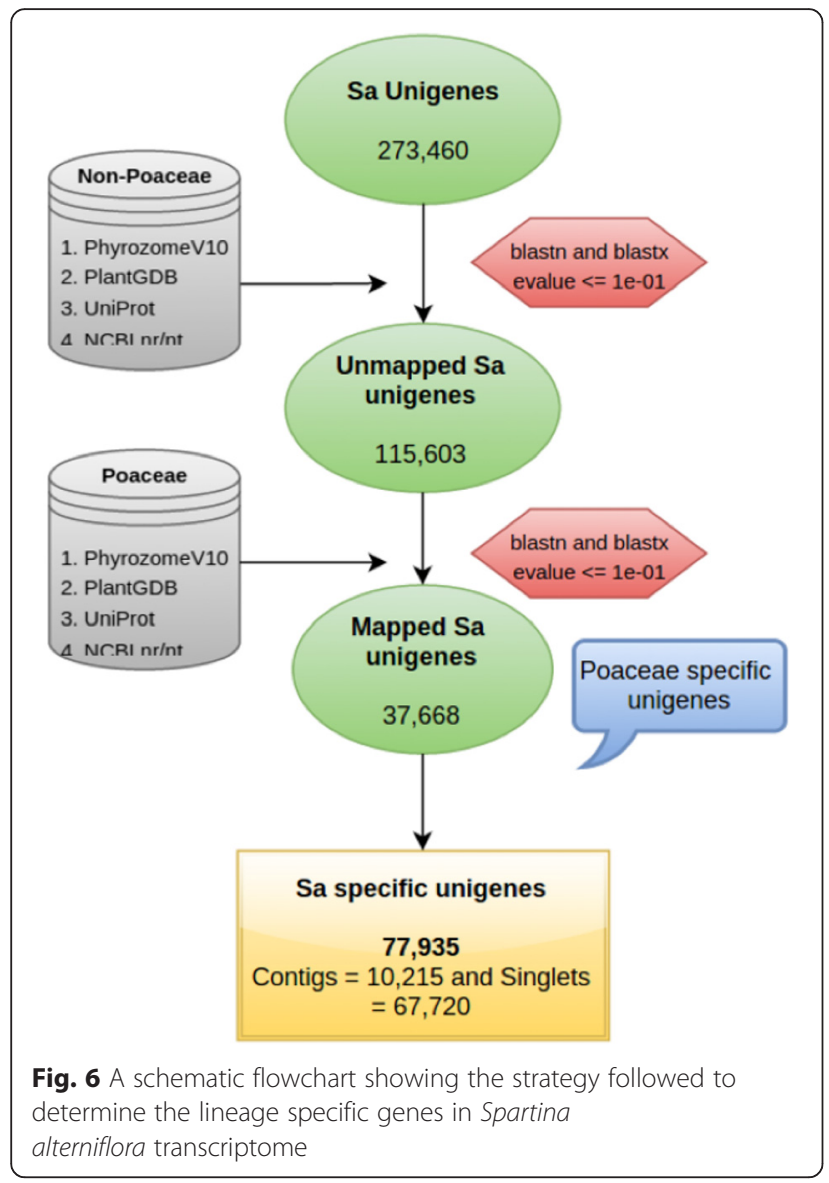

marsh grass. The differential gene expression analysis showed that genes involved in DNA/RNA binding (transcription factors), ion transport and protein kinase activities were upregulated by at least 2-fold ( $\log 2$ of fold change) under salt compared to control (Fig. 7).

\section{Transcription factor encoding genes}

Stress response in plants is dependent on the transcriptional control of stress responsive genes [54]. Identification and characterization of transcription factors overexpressed under salt stress will be helpful to elucidate the salt stress tolerance mechanisms in S. alterniflora and other halophytes towards engineering of the salt sensitive crops for improved salt stress tolerance [55]. Several salt responsive transcription factors were reported in previous studies based on the small-scale EST sequencing of S. alterniflora [28, 29]. Based on the search against all 84 families of transcription factors including transcription regulators in plant transcription factor database, $4462(1.63 \%)$ unigenes belonging to $54 \mathrm{TF}$ families and 22 other transcription regulators (TR) were identified in S. alterniflora leaf and root transcriptome.

Among the 76 families of TFs and TRs, single $\mathrm{C}(2)-\mathrm{C}(2)$ zinc finger-DNA-binding with one finger (C2C2-Dof) domain proteins, cysteine-rich polycomb-like protein (CPP), E2F-DP and GL1 enhancer binding protein (GeBP) transcription factors were highly expressed under salt in both leaf and root tissues of S. alterniflora. Of the $24 \mathrm{TFs} / \mathrm{TRs}$ that were upregulated under salt stress in leaf tissue, HSF, BBR/BPC and BSD TFs were significantly

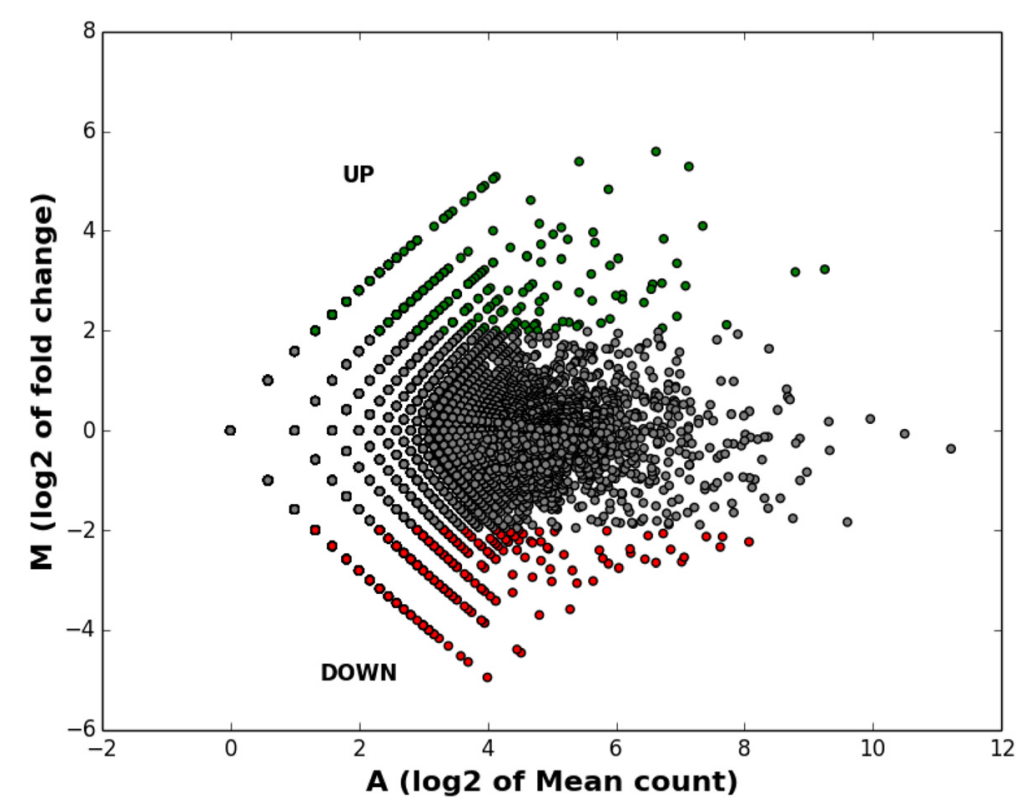

Fig. 7 The MA plot showing global differential expression of genes in leaf and root tissue of Spartina alterniflora. The red color indicates the downregulated genes (log2 fold change $\leq-2$ ) and green color indicates upregulated genes (log2 fold change $\geq 2$ ) 
upregulated. In root, among the 17 upregulated TFs/ TR under salt stress, ARF, AUX/IAA, CCAAT, E2F-DP and squamosa-promoter binding protein (SBP) were significantly enriched (Fig. 8). HSFs were highly induced in Arabidopsis by abiotic stresses, such as cold, salinity and osmotic stress [56]. AP2-EREBP and MYB-related TFs are known for their role in salt stress response [57-60]. The expression of ARF and AUX/IAA was reported to be upregulated under salt stress in sorghum [61]. TFs, such as HSF, BBR/BPC and BSD, which were significantly upregulated in the leaf tissue, were downregulated in root under salt stress, thus implying their tissue-preferred expression. Significantly upregulated salt-induced TFs in leaf and/or root tissues suggest their possible role in salt stress adaptation of S. alterniflora and calls for their functional characterization to implicate their possible use in regulon engineering for tolerance to high salinity in plants.

\section{Salt induced transporters}

To sustain under high salinity, plants maintain ion homeostasis. Salt tolerance in halophytes is dependent upon regulated uptake and accumulation/ compartmentalization of $\mathrm{Na}^{+}, \mathrm{K}^{+}$and $\mathrm{Cl}^{-}[12,62]$. The regulation and maintenance of high $\mathrm{K}^{+} / \mathrm{Na}^{+}$level is necessary for the halophytes to cope with salt stress and for normal plant growth [63]. The uptake of salt and its transport through cell is regulated by various transmembrane proteins. Plants maintains the $\mathrm{Na}^{+}$ and $\mathrm{K}^{+}$level by employing plasma membrane and

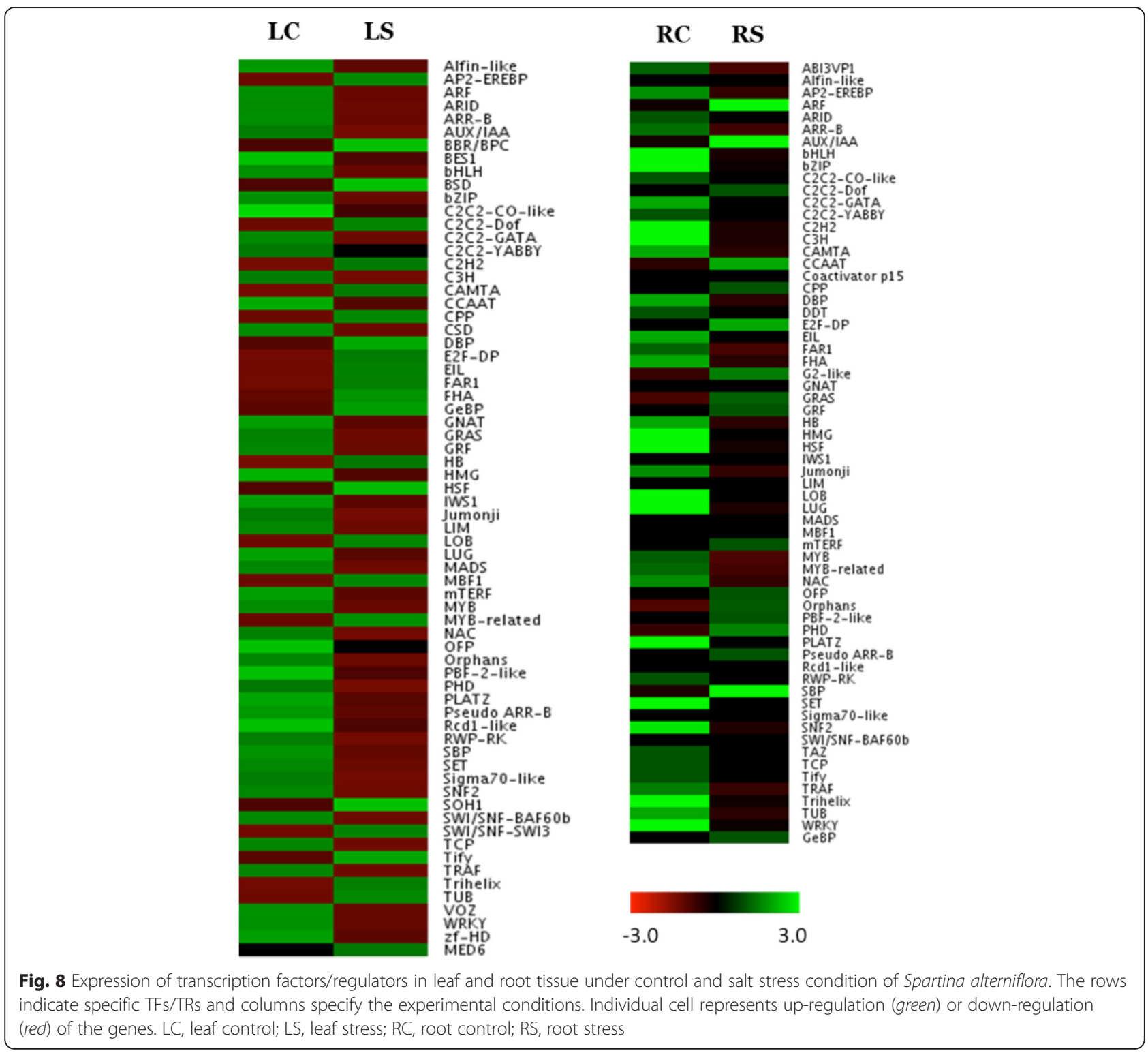


vacuolar $\mathrm{Na}^{+} / \mathrm{H}^{+}$-antiporters and high- and low-affinity $\mathrm{K}$ + channels [63]. In S. alterniflora in the present study, potassium transporter and $\mathrm{Na}^{+} / \mathrm{H}^{+}$antiporter, hydrogen ion transporters were highly upregulated under salinity. Several plants overexpressing $\mathrm{Na}^{+} / \mathrm{H}^{+}$transporters have shown improved salt tolerance (reviewed in [55]). $\mathrm{Na}^{+} / \mathrm{H}^{+}$ antiporter helps in maintaining low concentration of $\mathrm{Na}^{+}$ by active exclusion of $\mathrm{Na}^{+}$ions into vacuole and apoplast [64]. This secondary transport is energized by the membrane potential and proton gradient generated by the plasma membrane $\mathrm{H}^{+}$-ATPase and vacuolar $\mathrm{H}^{+}$-ATPase [12]. In halophytes and other salt tolerant plants, high salinity causes an increase in the activity of V-type and P-type ATPases (reviewed in [55]). The activity of P-type ATPases was increased under salt stress in an extreme halophyte Salicornia brachiata [65]. Increase in V-type $\mathrm{H}^{+}$-ATPase activity and $\mathrm{H}^{+}$transport was also observed under salt stress in sunflower roots [66]. Similar results were obtained in the present study where increased abundance of $\mathrm{Na}^{+} / \mathrm{H}^{+}$antiporter, P-type and V-type
ATPase transcripts were observed in the leaf tissue of $S$. alterniflora under salt stress (Fig. 9a).

Potassium transporters and $\mathrm{ABC}$ transporters were also overexpressed under salt stress in the leaf tissue of S. alterniflora; chloride transporters were also upregulated in leaf under salt stress (Fig. 9a). ABC transporters were reported to be up-regulated under salt stress in rice [63]. $\mathrm{Cl}^{-}$is the balancing anion for $\mathrm{Na}^{+}$ and it has an equivalent role to that of $\mathrm{Na}^{+}$in salt tolerance of halophytes [62]. These findings suggest that halophytes, such as S. alterniflora, maintain their salt tolerance ability by regulating uptake and accumulation of $\mathrm{Na}^{+}, \mathrm{K}^{+}$and $\mathrm{Cl}^{-}$through upregulation of selective stress-related transporters.

\section{Phosphatases/kinases}

Differential gene expression analysis showed that CDPK/ SnRK family of protein kinases, Casein kinase (CK) family, cyclin-dependent kinase family, serine-threonine protein kinase family, Mitogen activated protein kinases
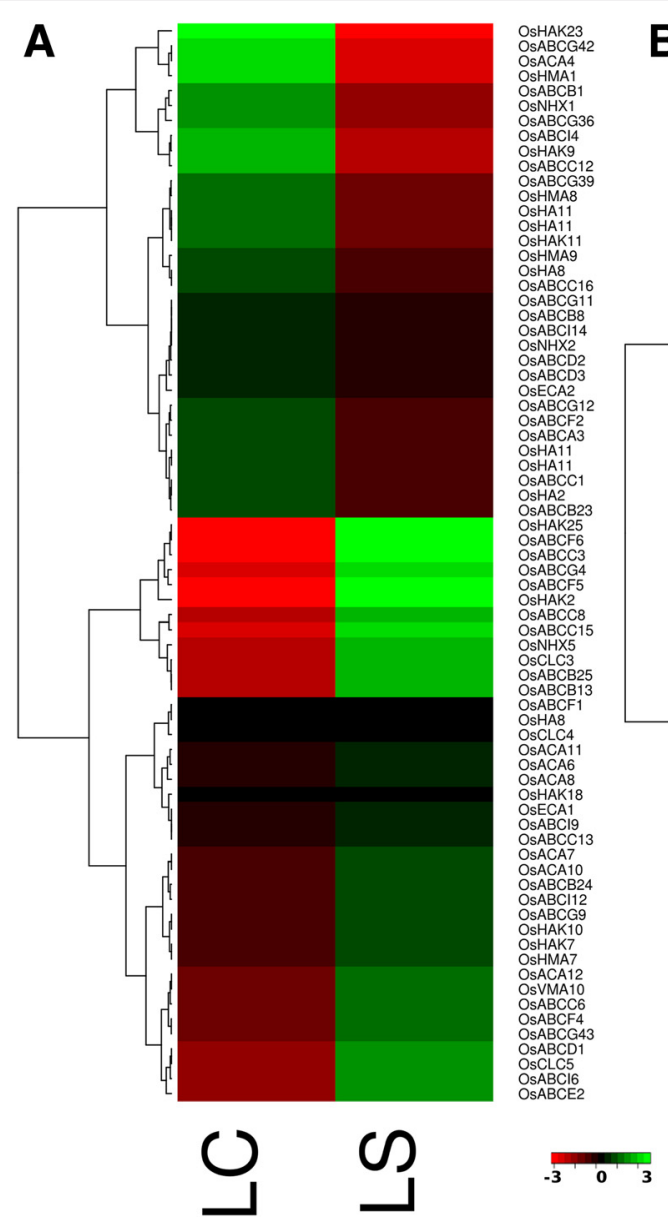

B

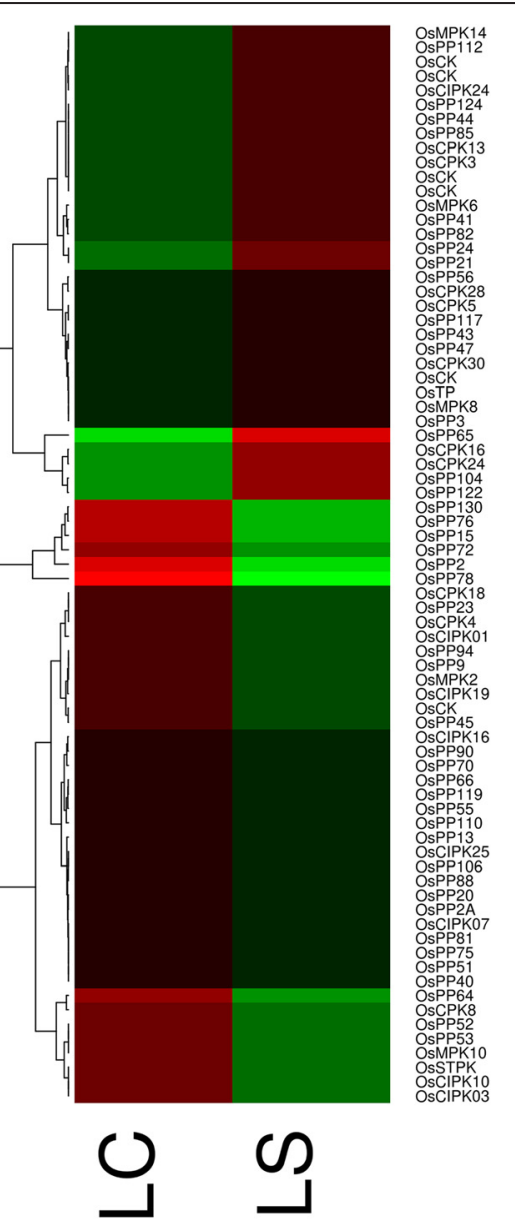

Fig. 9 Expression of transporters (a) and phosphatases/kinases (b) in leaf tissue under control and salt stress condition of Spartina alterniflora. The rows indicate specific transporters/phophatases/kinases and columns specify the experimental conditions. Each individual cell represents upregulation (green) or down-regulation (red) of the genes. LC, leaf control; LS, leaf stress 
(MAPK) family, CBL protein kinase, and protein phosphatase family genes were up-regulated under salt stress in S. alterniflora (Fig. 9b) by $\log 2$ fold change of $\geq 2$. $\mathrm{Ca}^{2+}$ signaling under the regulation of $\mathrm{Ca}^{2+}$-dependent kinases plays an important role in controlling cellular processes in response to abiotic stresses such as drought, cold and high salinity [67, 68]. Similarly, expression of mitogen activated protein kinases (MAPK) has been shown to improve abiotic stress tolerance in plants [69]. Protein phosphatases, such as PP2C, were up-regulated by $\log 2$ fold change $\geq 2$ in $S$. alterniflora under salt stress (Fig. 9b). The conserved domain analysis using PFAM and SMART database revealed that only 113 out of $1655 S$. alterniflora transcripts contained the phosphatase domain, and PP2C was the major class of protein phosphatase gene in S. alterniflora; similar result was reported in rice [70].

Heat shock proteins (HSPs) and heat shock factors (HSFs) were among other genes that were upregulated
( $\log 2$ fold change $\geq 2$ ) in S. alterniflora under salt. HSPs, HSFs and protein phosphatases are known to be differentially regulated under salt stress [56, 70, 71]. Semiquantitative RT-PCR analysis and heatmap of a selected set of genes representing different groups validated their time and tissue-dependent differential expression under salt stress (Fig. 10a and b).

\section{Microsatellite analysis}

Scanning of all 273,460 unigenes representing 105.5 $\mathrm{Mbp}$ of the S. alterniflora genome for the presence of SSRs using MIcroSAtellite (MISA) Perl Script [72] showed that $9457(3.45 \%)$ unigenes contained at least one SSR and $920(0.33 \%)$ unigenes contained more than one SSR. The identified SSRs were either perfect (containing single motif repeat) or compound (contains two or more SSRs separated by $\leq 100 \mathrm{bp}$ ). Altogether, 10,805 SSRs were identified of which 1132 were compound
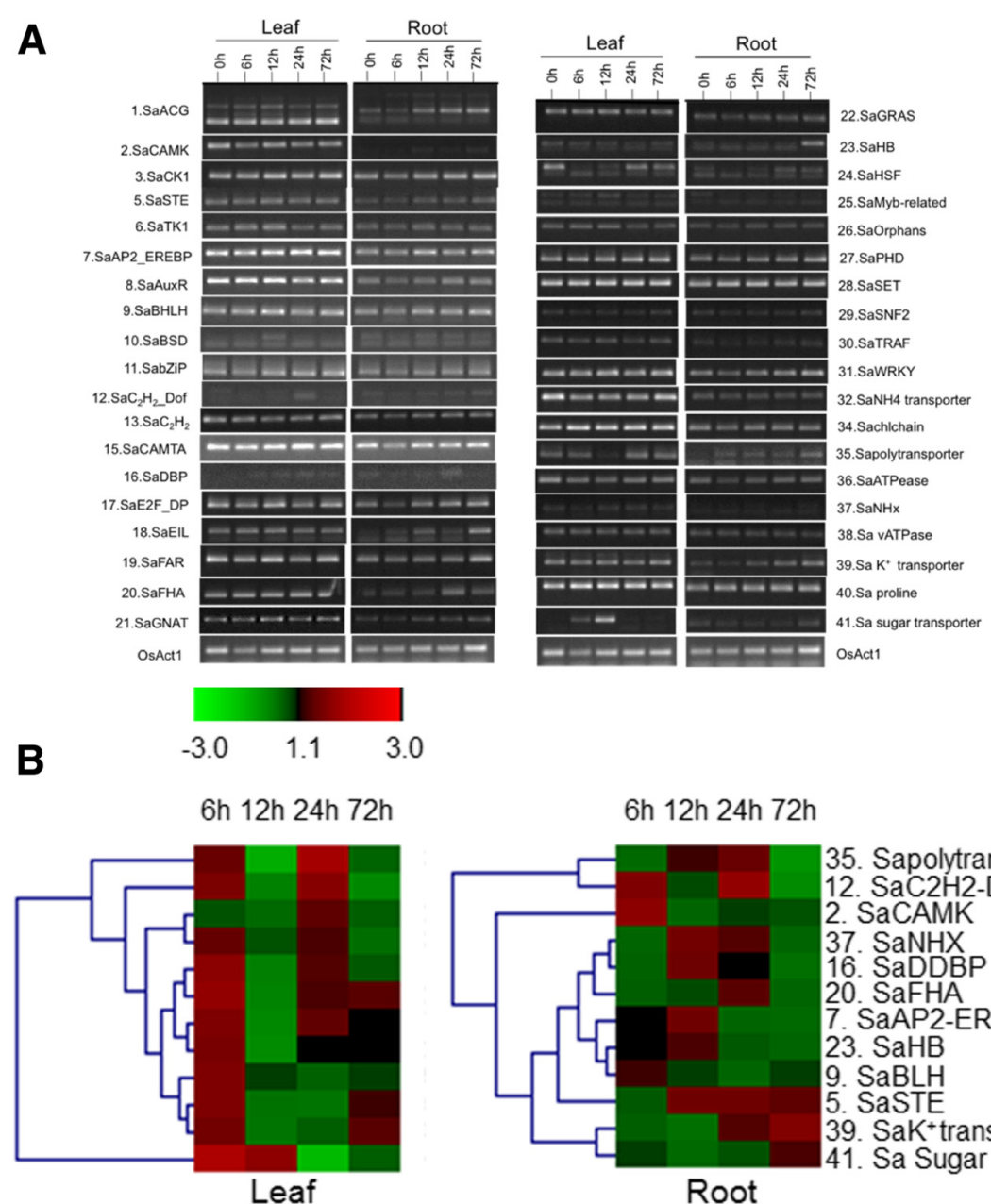

$6 \mathrm{~h} 12 \mathrm{~h} 24 \mathrm{~h} 72 \mathrm{~h}$

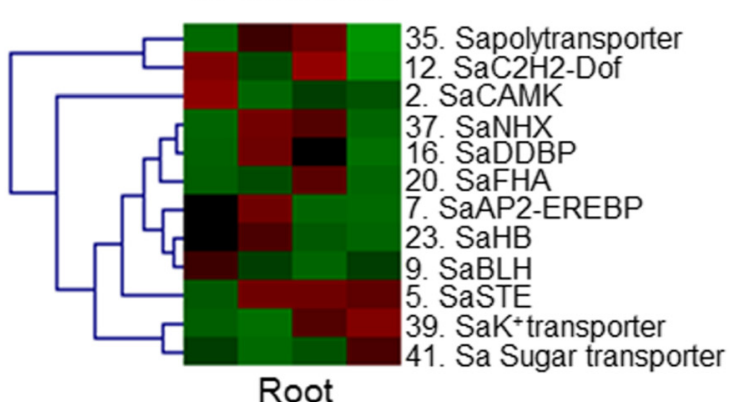

Fig. 10 a Semiquantitative reverse transcription PCR (SqRT-PCR) and $\mathbf{b}$ heatmap of expression of a selected set of genes under control and different time points under salt stress in leaf and root tissue of Spartina alterniflora 
Table 5 Analysis of microsatellite markers in Spartina alterniflora unigenes

\begin{tabular}{llllll}
\hline & LC & LS & RC & RS & Total \\
\hline $\begin{array}{l}\text { Total no. of sequences } \\
\text { analyzed }\end{array}$ & 73,552 & 68,346 & 72,199 & 59,363 & 273,460 \\
$\begin{array}{l}\text { Total size of sequences } \\
\text { analyzed (Mbp) }\end{array}$ & 30.34 & 30.29 & 23.82 & 21.02 & 105.48 \\
$\begin{array}{l}\text { Number of SSR } \\
\text { containing sequences }\end{array}$ & 3209 & 3188 & 1818 & 1242 & $9457(3.45 \%)$ \\
$\begin{array}{l}\text { Total number of } \\
\text { identified SSR }\end{array}$ & 3685 & 3654 & 2115 & 1351 & 10805 \\
$\begin{array}{l}\text { Number of sequences } \\
\text { containing more than }\end{array}$ & 334 & 343 & 175 & 68 & 920 \\
$\begin{array}{l}1 \text { SSR } \\
\text { Frequency of SSR found }\end{array}$ & & & & & \\
$\begin{array}{l}\text { Dinucleotide SSR } \\
\text { Trinucleotide SSR }\end{array}$ & 1378 & 1341 & 496 & 289 & $3504(32.42 \%)$ \\
$\begin{array}{l}\text { Tetranucleotide SSR } \\
\text { Pentanucleotide SSR }\end{array}$ & 8 & 25 & 43 & 9 & $90(0.83 \%)$ \\
Hexanucleotide SSR & 12 & 12 & 8 & 10 & $38(0.35 \%)$ \\
\hline
\end{tabular}

type. Of the total 10,805 SSRs, 4895 (45.3 \%) were mononucleotide repeats, 2237 (20.7 \%) dinucleotide repeats, $3504(32.4 \%)$ trinucleotide repeats, 90 (0.8\%) tetranucleotide repeats, 38 (0.4 \%) pentanucleotide repeats and $41(0.4 \%)$ were hexanucleotide repeats (Table 5). A total of 1185 (12.5\%) unigenes contained Class I SSRs (motif length of $\geq 20 \mathrm{bp}$ ) and 7666 (81.1\%) contained Class II SSRs (motif length $\geq 10$ bp but $<$ $20 \mathrm{bp}$ ). Trinucleotide repeats were $26.6 \%$ in Class I as compared to $36.7 \%$ in Class II SSRs. Tetra-, penta- and hexa-nucleotide repeats were least abundant in Class I SSRs and were not present in Class II SSRs (Fig. 11). Most of the SSRs were in the range of 5 to 15 repeat unit sizes, and the tri-nucleotide SSRs were the most abundant (Additional file 2: Figure S5). The average frequency of the SSRs in S. alterniflora transcriptome was found to be one per $9.76 \mathrm{~kb}$. The AG/CT (52.3\%) and CCG/CGG (31.6\%) were the most abundant di- and trinucleotide type repeats (Additional file 2: Figure S6). The high abundance of AG and AT dinucleotides and least abundance of CG dinucleotides in S. alterniflora unigenes (Additional file 2: Figure S6) was similar to the observation in rice [73, 74]. Similar to the present finding, rice, barley and wheat also had abundance of SSRs with CCG trinucleotide motifs [73].

A total 3637 pairs of SSR primers were designed from the unigenes containing simple SSR motifs. Sequences, annealing temperatures and expected amplicon sizes of all the primers are provided in Additional file 4: Table S2. Location of SSRs could be assigned to 1729 SSR containing unigenes. Among them, 975 (56.4 \%) were located in the protein coding region, 415 (24\%) were in the $5^{\prime}$-UTR and 339 (19.6\%) were in the $3^{\prime}$ UTR region. Of the 1,729 SSR containing unigenes, primer 3 could design SSR-flanking primers from only 1,338 unigenes (Additional file 4: Table S2). All genic SSRs tested were able to produce amplification products from all thirteen accessions (CP1 through CP 13) of S. alterniflora (Additional file 2: Figure S7). The average number of alleles per primer was 3.8 with a range of 3-6. Further, some of the SSRs produced accession-specific banding pattern. Large number of transcript-derived SSRs (ESSRs) identified in this study will enrich the genomic resources available for $S$. alterniflora [27, 75-77] for their use in variety identification, population genetic analysis, marker-trait analysis, and comparative genomics analysis because of their cross transferability etc.

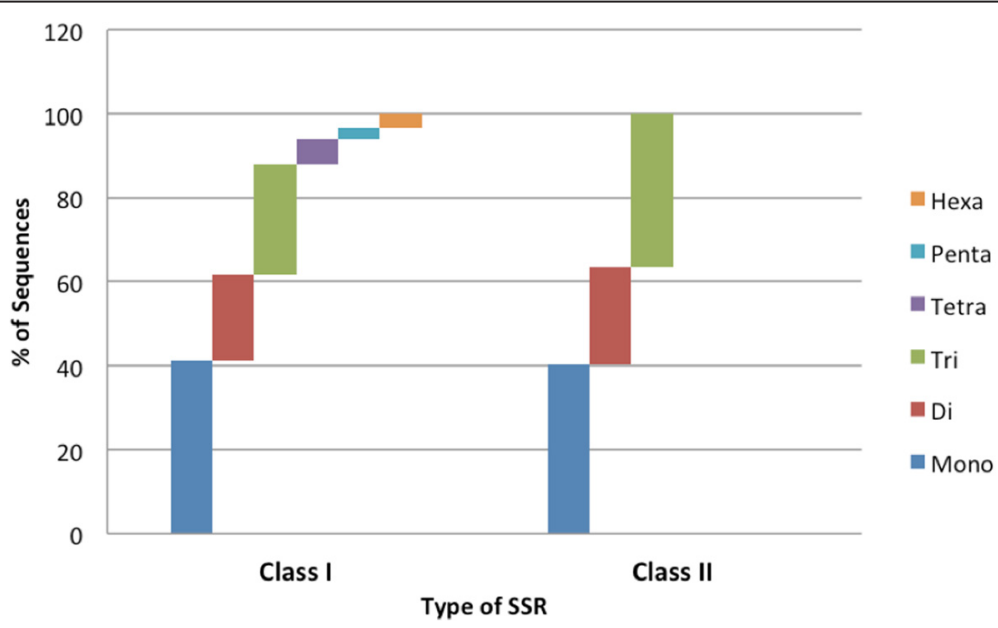

Fig. 11 Distribution of Class I and Class || SSRs identified from Spartina alterniflora transcriptome. Class I SSRs are $\geq 20$ bp while class || SSRs are $\geq 10$ bp but $<20$ bp in length 


\section{Conclusions}

The present study is of significance for plant scientists involved in understanding salt stress responses in halophytes vis-à-vis glycophytes, because this is the first study which explores the $S$. alterniflora leaf and root transcriptome on a genome-wide scale to identify the candidate genes that are regulated by salt stress. The sequence information obtained from this research will add to the available resources in Spartina species for studying abiotic stress responses in non-model plants. Further, engineering of plants for incorporating halophyte traits based on the genes identified can produce salt tolerant cultivars. High similarity of $S$. alterniflora genes with rice genes makes $S$. alterniflora a good halophyte model for engineering of rice for salt tolerance, assuming that ectopic expression of orthologous genes from $S$. alterniflora perform similar function in rice. The hypothesis is that $S$. alterniflora maintains the state of stress anticipatory preparedness in non-stressful conditions, and operates more specific gene regulation and possesses unique adaptation machinery(ies) under high and prolonged salinity. The higher frequency of genes of unknown function (hypothetical genes) upregulated under salinity provided further clues to the involvement of novel genes or processes in S. alterniflora for adaptation to extreme environment. Further, enhanced salt tolerance of rice engineered with $S$. alterniflora genes provides stronger evidence that it is rational to use $S$. alterniflora, being a grass species, as a model resource as proposed by Flowers and Colmer (2008) for understanding the evolution of halophytic adaptation as well as for subsequent translation of the information to improving salt stress tolerance of cereal crops including rice, a major food crop of global importance. The large number of SSRs reported in this study will be useful for genetic diversity studies in S. alterniflora. Because of their crossspecies transferability, the transcript-derived SSRs would facilitate genetic studies of different Spartina species for comparative genome analysis and evolutionary studies. Moreover, the SSRs derived from transcripts implicated in abiotic stress tolerances will be useful in identifying genotypes with stress tolerance alleles and candidate gene mapping.

\section{Additional files}

Additional file 1: The comparative analysis among Spartina alterniflora reads with reads of Salterniflora [34] and unigenes of S. pectinata [78]. (XLSX $154 \mathrm{~kb}$ )

Additional file 2: Figure S1. Percentage distribution of GC content between Spartina alterniflora and rice genes. Figure S2 Gene family distribution among the four monocots, Spartina alterniflora (Sa), Oryza sativa (Os), Sorghum bicolor (Sb) and Zea mays ( $\mathrm{Zm})$. The homologous genes from each monocot species were clustered to represent gene family. The number of homologous genes shared by different species is represented by gene families at intersection. Figure S3 Functional GO terms for gene families specific to Spartina alterniflora indicating coverage of different functional category genes specific to S. alterniflora. Figure S4 A histogram showing the GC content distribution in different sets of genes of Spartina alterniflora. NP, set of genes having similarity outside of poaceae; PS, poaceae specific genes; All, whole S. alterniflora transcriptome; and SS, S. alterniflora-specific genes. Figure S5 Distribution of different repeat unit size of the SSRs identified in Spartina alterniflora transcriptome. Figure S6 Distribution of different types of SSR motifs in Spartina alterniflora unigenes. Figure S7 Representative gel showing DNA profile of 13 (CP1 through CP13) Spartina alterniflora accessions produced by five SSR primers derived from the contigs. (PPTX $778 \mathrm{~kb}$ )

Additional file 3: Table S1. Protein families found in Spartina alterniflora unigenes retrieved from Pfam database. (XLSX 229 kb)

Additional file 4: Table S2. Simple sequence repeats (SSRs), flanking primers and their predicted location in Spartina alterniflora unigenes. (XLSX $357 \mathrm{~kb})$

\section{Acknowledgements}

The authors acknowledge Dr. Julio Solis for his valuable suggestions during the assembly of the sequence reads. This manuscript is approved for publication by the Louisiana Agricultural Experiment Station as MS\# 2016-306-28550.

\section{Funding}

The research was funded by a special grant from the United State Department of Agriculture-National Institute of Food and Agriculture (USDA-NIFA) and the Biotechnology AgCenter Inter-Disciplinary Team (BAIT) of the Louisiana State University Agricultural Center. The funding agencies had no role in the design of the study and collection, analysis, and interpretation of data and in writing the manuscript.

\section{Availability of data and materials}

The datasets generated during the current study in the form of raw sequence reads of the leaf and root transcriptome of Spartina alterniflora under control and salt stress are available at the NCBI SRA database under Bioproject

Accession No. PRJNA302231 (www.ncbi.nlm.nih.gov/bioproject/PRJNA302231).

\section{Authors' contributions}

NB conceived and designed the experiment. RB and SS analyzed the data. VRM and LES performed the laboratory experiments. RB and NB wrote the manuscript. All authors read and approved the final manuscript.

Competing interests

The authors declare that they have no competing interests.

Consent for publication

Not applicable.

Ethics approval and consent to participate Not applicable.

\section{Author details}

${ }^{1}$ School of Plant, Environmental and Soil Sciences, Louisiana State University Agricultural Center, Baton Rouge, LA 70803, USA. ²Department of Genetics and Biochemistry, Clemson University, Clemson, SC 29634, USA. ${ }^{3}$ Current address: Centro de Investigaciones Biotecnológicas del Ecuador (CIBE), Km 30.5 Via Perimetral, Guayaquil, Ecuador.

Received: 23 December 2015 Accepted: 13 August 2016

Published online: 19 August 2016

References

1. Munns R, Tester M. Mechanisms of salinity tolerance. Annu Rev Plant Biol. 2008:59:651-81.

2. Flowers TJ, Gaur PM, Gowda CLL, Krishnamurthy L, Samineni S, Siddique KHM, Turner NC, Vadez V, Varshney RK, Colmer TD. Salt sensitivity in chickpea. Plant Cell Environ. 2010;33(4):490-509.

3. Flowers TJ, Galal HK, Bromham L. Evolution of halophytes: multiple origins of salt tolerance in land plants. Funct Plant Biol. 2010;37(7):604-12. 
4. Kafi M, Khan MA, University of Birjand, Centre for Science and Technology of the Non-Aligned and Other Developing Countries. Crop and forage production using saline waters. Delhi: Daya Pub. House; 2008.

5. Rozema J, Flowers T. Ecology crops for a salinized world. Science. 2008; 322(5907):1478-80

6. Flowers TJ. Improving crop salt tolerance. J Exp Bot. 2004;55(396):307-19.

7. Denby K, Gehring C. Engineering drought and salinity tolerance in plants: lessons from genome-wide expression profiling in Arabidopsis. Trends Biotechnol. 2005;23(11):547-52.

8. Ayers RS, Westcot DW. Water quality for agriculture. FAO Irrig Drain. 1989;29:737-46

9. Flowers TJ, Hajibagheri MA, Clipson NJW. Halophytes. Q Rev Biol. 1986; 61(3):313-37.

10. Greenway H, Munns R. Mechanisms of salt tolerance in non-halophytes. Annu Rev Plant Physiol. 1980;31:149-90.

11. Rengasamy P, Chittleborough D, Helyar K. Root-zone constraints and plantbased solutions for dryland salinity. Plant Soil. 2003;257(2):249-60.

12. Flowers TJ, Colmer TD. Salinity tolerance in halophytes. New Phytol. 2008; 179(4):945-63.

13. Khan MA, Ungar IA, Showalter AM. Salt stimulation and tolerance in an intertidal stem-succulent halophyte. J Plant Nutr. 2005;28(8):1365-74.

14. Epstein E, Norlyn JD, Rush DW, Kingsbury RW, Kelley DB, Cunningham GA, Wrona AF. Saline culture of crops - a genetic approach. Science. 1980; 210(4468):399-404

15. Inan G, Zhang Q, Li PH, Wang ZL, Cao ZY, Zhang H, Zhang CQ, Quist TM, Goodwin SM, Zhu JH, et al. Salt cress. A halophyte and cryophyte Arabidopsis relative model system and its applicability to molecular genetic analyses of growth and development of extremophiles. Plant Physiol. 2004;135(3):1718-37.

16. Wang SM, Zhang JL, Flowers TJ. Low-affinity $\mathrm{Na}+$ uptake in the halophyte Suaeda maritima. Plant Physiol. 2007;145(2):559-71.

17. Taji T, Seki M, Satou M, Sakurai T, Kobayashi M, Ishiyama K, Narusaka Y, Narusaka M, Zhu JK, Shinozaki K. Comparative genomics in salt tolerance between Arabidopsis and Arabidopsis-related halophyte salt cress using Arabidopsis microarray. Plant Physiol. 2004;135(3):1697-709.

18. Gong QQ, Li PH, Ma SS, Rupassara SI, Bohnert HJ. Salinity stress adaptation competence in the extremophile Thellungiella halophila in comparison with its relative Arabidopsis thaliana. Plant J. 2005;44(5):826-39.

19. Kant $S$, Kant $P$, Raveh E, Barak S. Evidence that differential gene expression between the halophyte, Thellungiella halophila, and Arabidopsis thaliana is responsible for higher levels of the compatible osmolyte proline and tight control of $\mathrm{Na}(+)$ uptake in T. halophila. Plant Cell Environ. 2006;29(7):1220-34.

20. Tester $\mathrm{M}$, Bacic $\mathrm{A}$. Abiotic stress tolerance in grasses. From model plants to crop plants. Plant Physiol. 2005;137(3):791-3.

21. Moller IS, Tester M. Salinity tolerance of Arabidopsis: a good model for cereals? Trends Plant Sci. 2007;12(12):534-40.

22. Bradley PM, Morris JT. Relative Importance of ion exclusion, secretion and accumulation in Spartina Alterniflora Loisel. J Exp Bot. 1991;42(245):1525-32.

23. Wyn Jones RG, Storey R, Leigh RA, Ahmad N, Pollard A. A hypothesis on

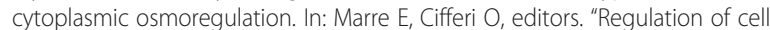
membrane activities in plants". Amsterdam: Elsevier; 1977. p. 121-36.

24. Drake BG, Gallagher JL. Osmotic potential and turgor maintenance in Spartina alterniflora Loisel. Oecologia. 1984;62(3):368-75.

25. Longstreth DJ, Strain BR. Effects of salinity and illumination on photosynthesis and water-balance of Spartina alterniflora-Loisel. Oecologia. 1977;31(2):191-9.

26. Marchant CJ. Evolution in Spartina (Gramineae): II. Chromosomes, basic relationships and the problem of S. $\times$ townsendii agg. Bot J Linn Soc London. 1968:60:381-409.

27. Baisakh N, Subudhi PK, Arumuganathan K, Parco AP, Harrison SA, Knott CA Materne MD. Development and interspecific transferability of genic microsatellite markers in Spartina spp. with different genome size. Aquat Bot. 2009;91(4):262-6.

28. Baisakh N, Subudhi PK, Parami NP. cDNA-AFLP analysis reveals differential gene expression in response to salt stress in a halophyte Spartina alterniflora Loisel. Plant Sci. 2006;170(6):1141-9.

29. Baisakh N, Subudhi PK, Varadwaj P. Primary responses to salt stress in a halophyte, smooth cordgrass (Spartina alterniflora Loisel.). Funct Integr Genomics. 2008;8(3):287-300.

30. Baisakh N, RamanaRao MV, Rajasekaran K, Subudhi P, Janda J, Galbraith D, Vanier C, Pereira A. Enhanced salt stress tolerance of rice plants expressing a vacuolar H plus -ATPase subunit c1 (SaVHAc1) gene from the halophyte grass Spartina alterniflora Loisel. Plant Biotechnol J. 2012;10(4):453-64.
31. Joshi R, Ramanarao MV, Baisakh N. Arabidopsis plants constitutively overexpressing a myo-inositol 1-phosphate synthase gene (SalNO1) from the halophyte smooth cordgrass exhibits enhanced level of tolerance to salt stress. Plant Physiol Bioch. 2013:65:61-6.

32. Joshi R, Ramanarao MV, Lee S, Kato N, Baisakh N. Ectopic expression of ADP ribosylation factor 1 (SaARF1) from smooth cordgrass (Spartina alterniflora Loisel) confers drought and salt tolerance in transgenic rice and Arabidopsis. Plant Cell Tiss Org Cult. 2014;117(1):17-30.

33. Ainouche ML, Fortune PM, Salmon A, Parisod C, Grandbastien MA, Fukunaga K, Ricou M, Misset MT. Hybridization, polyploidy and invasion: lessons from Spartina (Poaceae). Biol Invasions. 2009;11(5):1159-73.

34. de Carvalho JF, Poulain J, Da Silva C, Wincker P, Michon-Coudouel S, Dheilly A, Naquin D, Boutte J, Salmon A, Ainouche M. Transcriptome de novo assembly from next-generation sequencing and comparative analyses in the hexaploid salt marsh species Spartina maritima and Spartina alterniflora (Poaceae). Heredity. 2013;110(2):181-93.

35. Huang XQ, Madan A. Cap3: A DNA sequence assembly program. Genome Res. 1999;9(9):868-77.

36. Langmead B, Trapnell C, Pop M, Salzberg SL. Ultrafast and memory-efficient alignment of short DNA sequences to the human genome. Genome Biol. 2009;10(3):R25.

37. Maere S, Heymans K, Kuiper M. BiNGO: a Cytoscape plugin to assess overrepresentation of Gene Ontology categories in Biological Networks. Bioinformatics. 2005;21(16):3448-9.

38. Benjamini $Y$, Hochberg $Y$. Controlling the false discovery rate - a practical and powerful approach to multiple testing. J Roy Stat Soc B Met. 1995;57(1): 289-300.

39. Mulder NJ, Apweiler R. Tools and resources for identifying protein families, domains and motifs. Genome Biol. 2002;3(1):reviews2001.1-reviews2001.8. 10.1186.

40. Bateman A, Birney E, Cerruti L, Durbin R, Etwiller L, Eddy SR, Griffiths-Jones S, Howe KL, Marshall M, Sonnhammer ELL. The Pfam protein families database. Nucleic Acids Res. 2002;30(1):276-80.

41. Enright AJ, Van Dongen S, Ouzounis CA. An efficient algorithm for largescale detection of protein families. Nucleic Acids Res. 2002;30(7):1575-84.

42. Perez-Rodriguez P, Riano-Pachon DM, Correa LGG, Rensing SA, Kersten B, Mueller-Roeber B. PInTFDB: updated content and new features of the plant transcription factor database. Nucleic Acids Res. 2010;38:D822-7.

43. Lee S, Rajasekaran K, Ramanarao MV, Bedre R, Bhatnagar D, Baisakh N. Identifying cotton (Gossypium hirsutum L.) genes induced in response to Aspergillus flavus infection. Physiol Mol Plant Pathol. 2012;80:35-40.

44. Dardick C, Chen J, Richter T, Ouyang S, Ronald P. The rice kinase database. A phylogenomic database for the rice kinome. Plant Physiol. 2007;143(2):579-86.

45. Wang LK, Feng ZX, Wang X, Wang XW, Zhang XG. DEGseq: an R package for identifying differentially expressed genes from RNA-seq data. Bioinformatics. 2010;26(1):136-8.

46. Parchman TL, Geist KS, Grahnen JA, Benkman CW, Buerkle CA. Transcriptome sequencing in an ecologically important tree species: assembly, annotation, and marker discovery. BMC Genomics. 2010;11:180.

47. Swarbreck SM, Lindquist EA, Ackerly DD, Andersen GL. Analysis of leaf and root transcriptomes of soil-grown Avena barbata plants. Plant Cell Physiol. 2011;52(2):317-32

48. Wang $Z Y$, Fang $B P$, Chen JY, Zhang XJ, Luo ZX, Huang LF, Chen XL, Li YJ. De novo assembly and characterization of root transcriptome using Illumina paired-end sequencing and development of CSSR markers in sweetpotato (Ipomoea batatas). BMC Genomics. 2010;11:726.

49. Li DJ, Deng Z, Qin B, Liu XH, Men ZH. De novo assembly and characterization of bark transcriptome using Illumina sequencing and development of EST-SSR markers in rubber tree (Hevea brasiliensis Muell. Arg.). BMC Genomics. 2012;13:192.

50. Chelaifa H, Mahe F, Ainouche M. Transcriptome divergence between the hexaploid salt-marsh sister species Spartina maritima and Spartina alterniflora (Poaceae). Mol Ecol. 2010;19(10):2050-63.

51. Lin HN, Moghe G, Ouyang S, lezzoni A, Shiu SH, Gu X, Buell CR. Comparative analyses reveal distinct sets of lineage-specific genes within Arabidopsis thaliana. BMC Evol Biol. 2010;10:41.

52. Campbell MA, Zhu W, Jiang N, Lin H, Ouyang S, Childs KL, Haas BJ, Hamilton JP, Buell CR. Identification and characterization of lineage-specific genes within the Poaceae. Plant Physiol. 2007;145(4):1311-22.

53. Garg R, Patel RK, Jhanwar S, Priya P, Bhattacharjee A, Yadav G, Bhatia S, Chattopadhyay D, Tyagi AK, Jain M. Gene discovery and tissue-specific 
transcriptome analysis in chickpea with massively parallel pyrosequencing and web resource development. Plant Physiol. 2011;156(4):1661-78.

54. Singh KB, Foley RC, Onate-Sanchez L. Transcription factors in plant defense and stress responses. Curr Opin Plant Biol. 2002;5(5):430-6.

55. Subudhi PK, Baisakh N. Spartina alterniflora Loisel., a halophyte grass model to dissect salt stress tolerance. In Vitro Cell Dev Plant. 2011;47(4):441-57.

56. Swindell WR, Huebner M, Weber AP. Transcriptional profiling of Arabidopsis heat shock proteins and transcription factors reveals extensive overlap between heat and non-heat stress response pathways. BMC Genomics. 2007;8:125.

57. Xiong LM, Schumaker KS, Zhu JK. Cell signaling during cold, drought, and salt stress. Plant Cell. 2002;14:S165-83.

58. Shen YG, Zhang WK, Yan DQ, Du BX, Zhang JS, Liu Q, Chen SY. Characterization of a DRE-binding transcription factor from a halophyte Atriplex hortensis. Theor Appl Genet. 2003;107(1):155-61.

59. Tang MJ, Liu XF, Deng HP, Shen SH. Over-expression of JcDREB, a putative AP2/EREBP domain-containing transcription factor gene in woody biodiesel plant Jatropha curcas, enhances salt and freezing tolerance in transgenic Arabidopsis thaliana. Plant Sci. 2011;181(6):623-31.

60. Katiyar A, Smita S, Lenka SK, Rajwanshi R, Chinnusamy V, Bansal KC. Genome-wide classification and expression analysis of MYB transcription factor families in rice and Arabidopsis. BMC Genomics. 2012;13:544.

61. Wang SK, Bai YH, Shen CJ, Wu YR, Zhang SN, Jiang DA, Guilfoyle TJ, Chen M, Qi YH. Auxin-related gene families in abiotic stress response in Sorghum bicolor. Funct Integr Genomics. 2010;10(4):533-46.

62. Glenn EP, Brown JJ, Blumwald E. Salt tolerance and crop potential of halophytes. Crit Rev Plant Sci. 1999;18(2):227-55.

63. Jamil A, Riaz S, Ashraf M, Foolad MR. Gene expression profiling of plants under salt stress. Crit Rev Plant Sci. 2011;30(5):435-58.

64. Serrano R, Mulet JM, Rios G, Marquez JA, de Larrinoa IF, Leube MP, Mendizabal I, Pascual-Ahuir A, Proft M, Ros R, et al. A glimpse of the mechanisms of ion homeostasis during salt stress. J Exp Bot. 1999;50:1023-36.

65. Jha B, Agarwal PK, Reddy PS, Lal S, Sopory SK, Reddy MK. Identification of salt-induced genes from Salicornia brachiata, an extreme halophyte through expressed sequence tags analysis. Genes Genet Syst. 2009;84(2):111-20.

66. Ballesteros $\mathrm{E}$, Blumwald $\mathrm{E}$, Donaire JP, Belver $\mathrm{A}$. $\mathrm{Na}+/ \mathrm{H}+$ antiport activity in tonoplast vesicles isolated from sunflower roots induced by $\mathrm{NaCl}$ stress. Physiol Plant. 1997;99(2):328-34.

67. Franz S, Ehlert B, Liese A, Kurth J, Cazale AC, Romeis T. Calcium-dependent protein kinase cpk21 functions in abiotic stress response in Arabidopsis thaliana. Mol Plant. 2011;4(1):83-96.

68. Saijo Y, Kinoshita N, Ishiyama K, Hata S, Kyozuka J, Hayakawa T, Nakamura T, Shimamoto K, Yamaya T, Izui K. A Ca2 +-dependent protein kinase that endows rice plants with cold- and salt-stress tolerance functions in vascular bundles. Plant Cell Physiol. 2001:42(11):1228-33.

69. Sinha AK, Jaggi M, Raghuram B, Tuteja N. Mitogen-activated protein kinase signaling in plants under abiotic stress. Plant Signal Behav. 2011;6(2):196-203.

70. Singh A, Giri J, Kapoor S, Tyagi AK, Pandey GK. Protein phosphatase complement in rice: genome-wide identification and transcriptional analysis under abiotic stress conditions and reproductive development. BMC Genomics. 2010;11:435

71. Baisakh N, Subudhi PK. Heat stress alters the expression of salt stress induced genes in smooth cordgrass (Spartina alterniflora L.). Plant Physiol Biochem. 2009:47(3):232-5.

72. Thiel T, Michalek W, Varshney RK, Graner A. Exploiting EST databases for the development and characterization of gene-derived SSR-markers in barley (Hordeum vulgare L.). Theor Appl Genet. 2003;106(3):411-22.

73. La Rota M, Kantety RV, Yu JK, Sorrells ME. Nonrandom distribution and frequencies of genomic and EST-derived microsatellite markers in rice, wheat, and barley. BMC Genomics. 2005;6:23.

74. Parida SK, Kumar KAR, Dalal V, Singh NK, Mohapatra T. Unigene derived microsatellite markers for the cereal genomes. Theor Appl Genet. 2006; 112(5):808-17.

75. Blum MJ, Sloop CM, Ayres DR, Strong DR. Characterization of microsatellite loci in Spartina species (Poaceae). Mol Ecol Notes. 2004;4(1):39-42.

76. Sloop CM, McGray HG, Blum MJ, Strong DR. Characterization of 24 additional microsatellite loci in Spartina species (Poaceae). Conserv Genet. 2005;6(6):1049-52.
77. Guo WX, Huang YL, He ZW, Yan YB, Zhou RC, Shi SH. Development and characterization of microsatellite loci for smooth cordgrass, Spartina alterniflora (Poaceae). Appl Plant Sci. 2013;1(1):reviews2001.1-reviews2001.8. 10.1186.

78. Gedye K, Gonzalez-Hernandez J, Ban YG, Ge XJ, Thimmapuram J, Sun FJ, Wright C, Ali S, Boe A, Owens V. Investigation of the transcriptome of prairie cord grass, a new cellulosic biomass crop. Plant Genome. 2010;3(2):69-80.

\section{Submit your next manuscript to BioMed Central and we will help you at every step:}

- We accept pre-submission inquiries

- Our selector tool helps you to find the most relevant journal

- We provide round the clock customer support

- Convenient online submission

- Thorough peer review

- Inclusion in PubMed and all major indexing services

- Maximum visibility for your research

Submit your manuscript at www.biomedcentral.com/submit
C Biomed Central 